\title{
Initiation of mineralization in bioprosthetic heart valves: Studies of alkaline phosphatase activity and its inhibition by $\mathrm{AlCl}_{3}$ or $\mathrm{FeCl}_{3}$ preincubations
}

\author{
Robert J. Levy* \\ Department of Pediatrics, University of Michigan, Ann Arbor, Michigan 48109
}

Frederick J. Schoen

Department of Pathology, Brigham and Women's Hospital and Harvard Medical School, Boston, Massachusetts 02115

William B. Flowers and S. Tyler Staelin

Department of Pediatrics, University of Michigan, Ann Arbor, Michigan 48109

The principal cause of the clinical failure of bioprosthetic heart valves fabricated from glutaraldehyde-pretreated porcine aortic valves is calcification. Other prostheses composed of tissue-derived and polymeric biomaterials also are complicated by deposition of mineral. We have previously demonstrated that: (a) Failure due to calcification of clinical bioprosthetic valves can be simulated by either a large animal circulatory model or subdermal implants in rodents. (b) Calcification of bioprosthetic tissue has complex host, implant, and mechanical determinants. (c) The initial calcification event in the rat subdermal model is the mineral deposition in devitalized cells intrinsic to the bioprosthetic tissue within 48 to $72 \mathrm{~h}$, followed later by collagen mineralization. (d) Initiation of bioprosthetic tissue mineralization, like that of physiological bone formation, has "matrix vesicles" as early nucleation sites. (e) Alkaline phosphatase (AP), an enzyme also associated with matrix vesicles involved in bone mineral nucleation, is present in both fresh and fixed bioprosthetic tissue at sites of initial mineralization. (f) Certain inhibitors of bioprosthetic tissue calcification (e.g., $\mathrm{Al}^{3+}, \mathrm{Fe}^{3+}$ ) are localized to the sites at which alkaline phosphatase is present. On the basis of these results, we hypothesize that alkaline phosphatase is a key element in the pathogenesis of mineralization of bioprosthetic tissue. In the present studies, we focused on the relationship of AP to early events in calcification, and the inhibition of both calcification and AP activity by $\mathrm{FeCl}_{3}$ and $\mathrm{AlCl}_{3}$ preincubations. Subdermal implants of glutaraldehyde pretreated bovine pericardium (GPBP) were done in 3-week-old rats. AP was characterized by enzymatic hydrolysis of paranitrophenyl phosphate (pnpp), and by histochemical studies. Calcification was evaluated chemically (by atomic adsorption spectroscopy) and morphologically (by light microscopy). The results of these studies are as follows: (a) Extractable AP activity is present in fresh but not glutaraldehyde-pretreated bovine pericardial tissue. However, histochemical studies reveal active AP within the intrinsic devitalized cells of GPBP, despite extended glutaraldehyde incubation. (b) Extrinsic AP is rapidly adsorbed following implantation, with peak activity at $72 \mathrm{~h}(424 \pm 67.2 \mathrm{~nm} \mathrm{pnpp} / \mathrm{mg}$ protein/ min enzyme activity [units]), but markedly lesser amounts at 21 days (96.8 \pm 3.9 units). (c) Simultaneously to the AP activity maximum, bulk calcification is initiated, with GPBP calcium levels rising from $1.2 \pm 0.1$ (unimplanted) to $2.4 \pm$

* To whom correspondence should be addressed at Department of Pediatrics, University of Michigan, R5014 Kresge II 0576, Ann Arbor, MI 48109.

Journal of Biomedical Materials Research, Vol. 25, 905-935 (1991)

(C) 1991 John Wiley \& Sons, Inc.

CCC 0021-9304/91/080905-31\$4.00 
$0.2 \mu \mathrm{g} / \mathrm{mg}$ at $72 \mathrm{~h}$, to $55.6 \pm 3.1 \mu \mathrm{g} / \mathrm{mg}$ at 21 days, despite a marked decline in AP activity at this later time. (d) Preincubation of GPBP in either $\mathrm{FeCl}_{3}$ or $\mathrm{AlCl}_{3}$, at concentrations $(0.1 \mathrm{M})$ which inhibited GPBP calcification, significantly reduce AP activity. We conclude that endogenous AP activity is present but not extractable in unimplanted GPBP fixed for extended periods. However, concurrent with the time of the onset of GPBP calcification in the rat subdermal model, AP adsorbed following implantation rises sharply to a maximum, thereby augmenting intrinsic enzyme. Preincubations of GPBP in either $\mathrm{AlCl}_{3}$ or $\mathrm{FeCl}_{3}$ not only prevent calcification, but also result in reduction in $\mathrm{AP}$ activity. These results strongly suggest that AP is an important cofactor in the mechanism of bioprosthetic valve mineralization and may be a fruitful target for anticalcification treatments.

\section{INTRODUCTION}

Deposition of calcium phosphates and other calcium salts (calcification) in and on biomaterials affects a wide variety of medical devices (reviewed in Refs. 1-3). Calcification is the principal cause of the clinical failure of heart valve bioprostheses fabricated from glutaraldehyde-pretreated porcine aortic valves and is an important complication of valves made of glutaraldehydepretreated bovine pericardium. ${ }^{4-10}$ The failure rate of porcine aortic valves is approximately $50 \%$ at $12-15$ years, with $>75 \%$ of failures resulting from calcification-induced stenosis or tearing (Fig. 1). ${ }^{6-10}$ In addition, calcification limits the use of valved human aortic homografts and bioprostheses, fabricated from dura mater and fascia lata, ${ }^{9,10}$ and has kept trileaflet polymer valves from the marketplace. ${ }^{11,12}$ Furthermore, the polyurethane bladders of experimental ventricular assist systems and artificial hearts calcify, leading to significant functional limitation that could eventually be of clinical importance. ${ }^{2,13-15}$ Calcific deposits also complicate contact lenses, intrauterine contraceptive devices, and urinary tract prostheses.

This manuscript derives from a decade of collaboration between two of us (RJL and FJS), focused on describing, understanding, and ultimately preventing bioprosthetic heart valve and other biomaterials calcification. In the first part of this communication, a contemporary review emphasizing our previous work on calcification defines the rationale of the second part, a study of a potentially critical factor in the mechanism of mineralization. This investigation extends the analogy between pathologic (dystrophic) calcification of bioprosthetic tissue (BPT) and physiologic mineralization of skeletal tissue, suggesting important directions for investigation and potentially prevention of biomaterials mineralization processes in general.

\section{REVIEW OF PREVIOUS WORK AND RATIONALE}

\section{Simulation of clinically observed calcification pathology by animal models}

Experimental models of BPT calcification include orthotopic tricuspid or mitral valve replacements or conduit-mounted valves in juvenile sheep or calves, and heterotopic tissue samples implanted either subdermally (subcutaneously) 

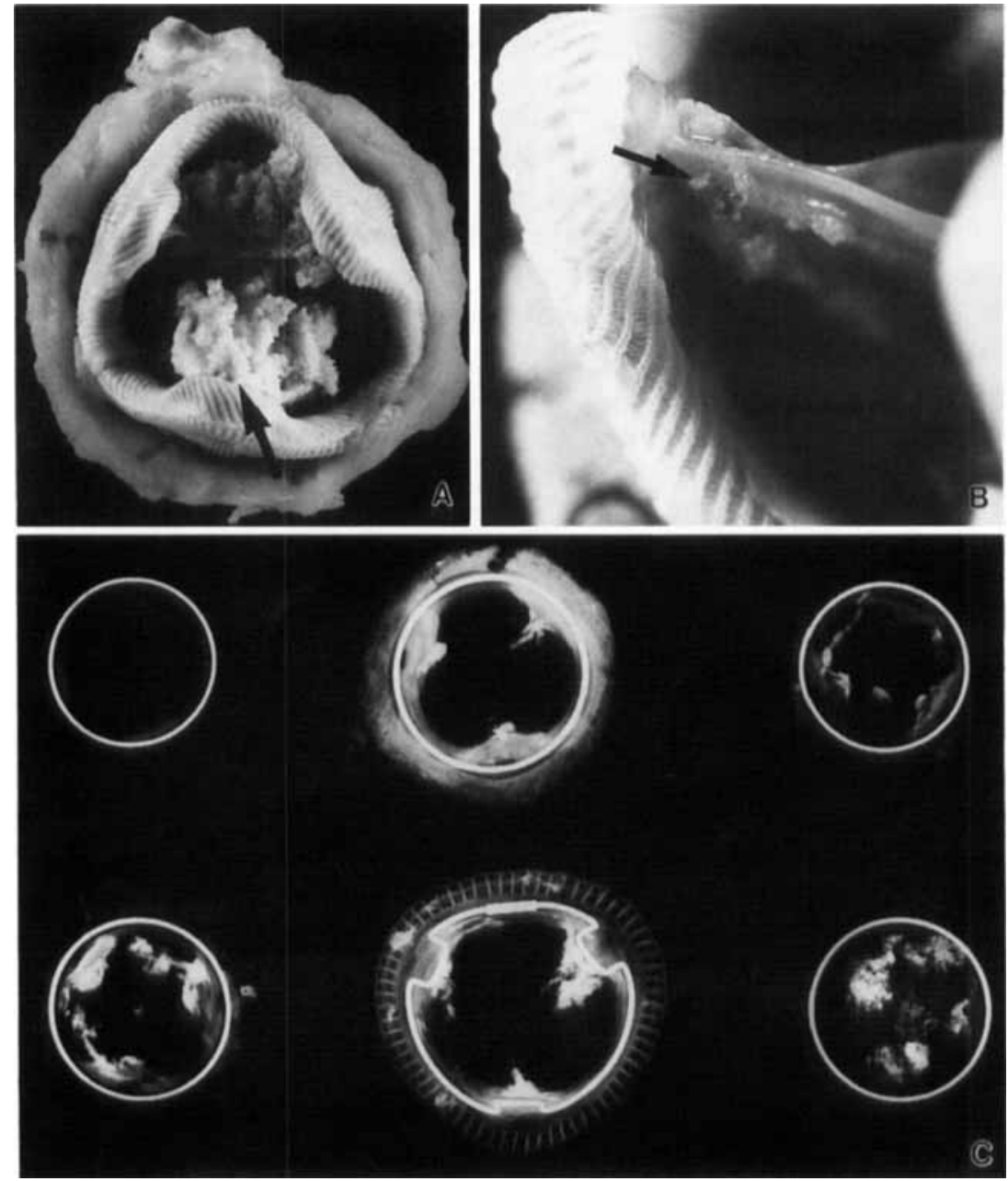

Figure 1. Clinical bioprosthetic valve calcification. (A) Gross photograph, from outflow aspect, of removed stenotic valve, demonstrating large calcific nodule (arrow). (B) Close-up photograph of valve with early bioprosthetic valve mineralization; illustrating intrinsic calcific deposits, with focal ulceration through the surface (arrow). (C) Composite radiograph of calcified porcine valve bioprostheses, demonstrating the various levels of mineralization, $1+$ thru $4+$. Top, uncalcified $(0), 1+$, and $2+$. Bottom $3+$, $3+$, and $4+$. Specimens illustrated are Hancock porcine valves, except the bottom row, middle, which is a Carpentier-Edwards porcine valve. [(C) Reproduced by permission from F. J. Schoen et al., "Chemically determined mineral content of explanted porcine aortic valve bioprostheses: correlation with radiographic assessment of calcification and clinical data," Circulation, 76, 1061 (1987).]

or in and around the heart (reviewed in Refs. 2, 6, and 8). In both circulatory and subcutaneous models, BPT calcifies progressively, with morphology similar to that observed in clinical specimens, but with markedly accelerated kinetics. Valves implanted into sheep or calves calcify extensively in 3 to 6 months, compared with the several years normally required for calcification of clinical bioprostheses. ${ }^{8,14,16-18}$ Even more dramatic acceleration is achieved in subcutaneous implants of BPT in young rats, in which levels comparable to 
those of failed clinical explants (200-225 $\mu \mathrm{g}$ calcium/mg tissue) occur in 8 weeks or less. ${ }^{17,19-21}$

The similar morphologic progression of calcification in different experimental models and in clinical bioprostheses suggests a common pathophysiology, independent of implant site, and dependent only on exposure of a susceptible substrate to a permissive environment. This concept, critical to evolving hypotheses for the pathophysiology of BPT calcification, does not exclude a possible regulatory role of either blood-borne substances or mechanical factors. We have utilized the subcutaneous implantation model extensively as a technically convenient, economically advantageous, and quantifiable model for investigating the pathobiology of mineralization, as well as for screening and understanding mechanisms of potential strategies for mineralization inhibition.

\section{Determinants of bioprosthetic tissue mineralization}

Calcification of BPT (and indeed, likely of biomaterials in general) depends on host, implant, and biomechanical factors (reviewed in Refs. 6-8). Host and implant factors are discussed in detail below (Table I). Moreover, clinical and experimental studies strongly suggest that dynamic mechanical stress and strain promote calcification (reviewed in Refs. 6-8, 22). Calcification of bioprosthetic valves is most pronounced in areas of leaflet flexion, where deformations are maximal (i.e., cuspal commissures and bases). However, because subcutaneous implants calcify with a morphology analogous to that observed in clinical and experimental circulatory implants, dynamic stress promotes, but is not a prerequisite for, calcification of BPT. This suggests that metabolic and implant factors alone are both necessary and sufficient. Nevertheless, calcification of subcutaneous BPT is enhanced in areas of tissue folds

TABLE I

Calcification of Subcutaneously Implanted Bioprosthetic Tissue (21-Day Implants)

\begin{tabular}{lcc}
\hline \multicolumn{1}{c}{ Experimental Condition } & $\begin{array}{c}\text { Calcium Content } \\
(\mu \mathrm{g} / \mathrm{mg} \text { tissue })\end{array}$ & Reference \\
\hline Unimplanted PAV cusp & $3 \pm 1$ & 19 \\
3-week-old recipient rat & $6 \pm 1$ & 19 \\
Untreated (fresh) PAV cusp & $108 \pm 16$ & 19 \\
Glutaraldehyde-treated PAV cusp & $114 \pm 8$ & 19 \\
Glutaraldehyde-treated bovine pericardium & $92 \pm 18$ & 19 \\
Millipore chamber-enclosed PAV cusp ${ }^{\mathrm{a}}$ & $57 \pm 6$ & 33 \\
Purified Type I collagen & & \\
6-8-month-old recipient rat & $13 \pm 4$ & 19 \\
3-week-old recipient mouse & $102 \pm 5$ & 23 \\
PAV $^{\mathrm{a}}$ in control (BALBc) mouse & $96 \pm 25$ & 23 \\
\hline PAV $^{\mathrm{a}}$ in nude (thymus-deficient) & & \\
\hline
\end{tabular}

Mean \pm SEM; PAV = porcine aortic valve.

*Highly glutaraldehyde crosslinked.

Reproduced by permission from F. J. Schoen and R. J. Levy, "Pathophysiology of bioprosthetic heart valve calcification," In Biological and Bioprosthetic Valves, E. Bodnar and M. H. Yacoub (eds.), Yorke, New York, 1986, p. 418. 
and bends, ${ }^{19}$ demonstrating that static mechanical deformation also potentiates mineralization. The mechanisms by which stress enhances calcification are presently uncertain.

Host metabolic factors regulate the rate of BPT mineralization (reviewed in Refs. 6-8). For example, young age and renal failure potentiate mineralization. In the rat subcutaneous model, in which BPT implanted in 8-month-old rats accumulate $<15 \%$ of the calcium accumulated in implants in 3-week-old recipients, the clinically observed age dependence of calcification rate is simulated. ${ }^{19}$ The specific basis for age-dependent kinetics is uncertain.

Neither nonspecific inflammation nor specific immunological responses appear to mediate BPT calcification. Tissue reaction to circulatory and subcutaneous porcine or pericardial valve implants is a classic foreign body reaction, primarily composed of nonlymphocytic mononuclear cells, particularly macrophages. ${ }^{4,5,10,19}$ Inflammatory cell penetration into BPT and host cell reaction to mineral deposits are generally minimal. Inflammation induces neither mineral deposition nor resorption. ${ }^{4,5,17,19,20}$ Moreover, neither the extent nor the morphology of mineralization in rat subcutaneous implants is altered by enclosure of valve cusps in chambers that prevent host cell contact with tissue, but allow free diffusion of extracellular fluid. ${ }^{19}$ In addition, BPT calcifies to the same extent whether implanted in immunologically competent hosts or congenitally athymic ("nude") mice, who have essentially no T-lymphocyte function. ${ }^{23}$ These experimental findings are supported by clinical data that show that second bioprosthetic heart valve replacements fail no sooner than initial replacements. ${ }^{24}$ Although several experimental studies have suggested that BPT remains immunogenic, ${ }^{25,26}$ despite both high collagen content and crosslinking, the presence of an immunological response has never been related to mineralization.

Although an inhibitory effect on mineralization of sodium warfarin was suggested by a retrospective study of patients with clinical bioprosthetic valves $^{27}$ and an experimental investigation of elastomeric blood pump sacs, ${ }^{13}$ we have been unable to demonstrate an inhibitory effect of warfarin on BPT calcification either in the calf circulatory system ${ }^{16}$ or the rat subcutaneous space, ${ }^{19}$ or on calcification of functioning cardiac assist device bladders. ${ }^{16}$

Tissue preparation is an important determinant of the propensity of BPT to calcify (reviewed in Refs. 6-8). In rat subcutaneous implants, pretreatment of BPT with an aldehyde crosslinking agent is a prerequisite for calcification; nonpreserved cusps do not mineralize. ${ }^{10,28}$ Glutaraldehyde-treated porcine aortic valve and bovine pericardium calcify comparably with respect to kinetics, extent, and morphology ${ }^{19,20,29}$ (Fig. 2). This suggests that the fundamental mechanisms of bioprosthetic tissue mineralization depend on specific biochemical modifications of implant microstructural components induced by aldehyde pretreatment.

\section{Localization and mechanisms of crystal formation}

The morphological features of experimental BPT mineralization are summarized in Figures 3 and 4. Ultrastructural examination demonstrates that 


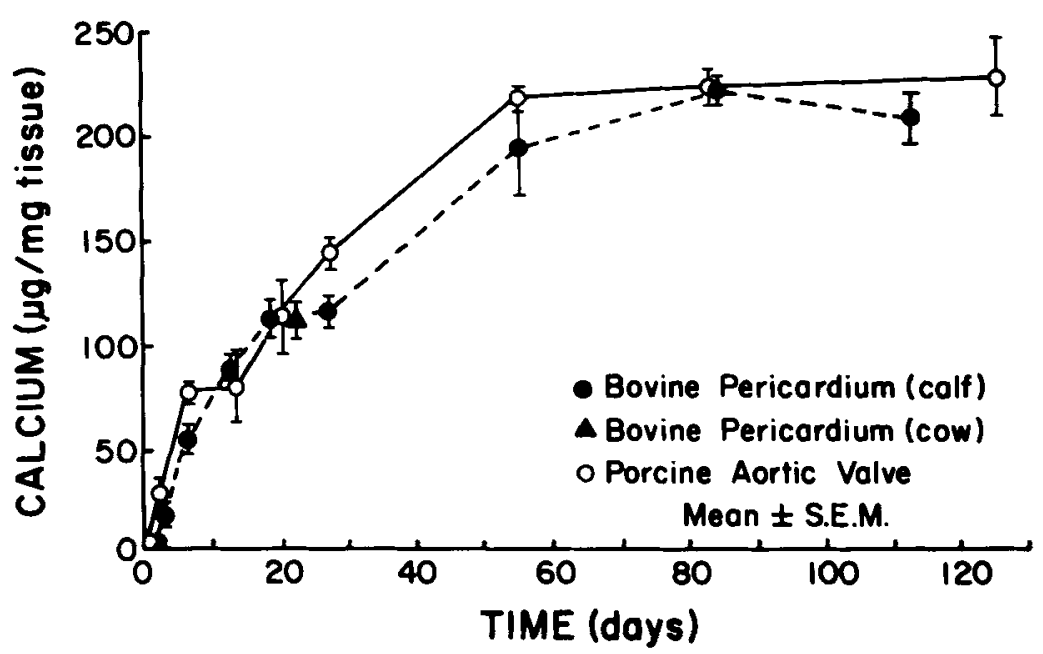

Figure 2. Progression of calcification (calcium assay by atomic absorption spectroscopy) in glutaraldehyde-pretreated porcine aortic valve and bovine pericardium implanted subcutaneously in rats. Calcification proceeds rapidly, with significant mineral accumulation following only 2 days, half maximal mineralization following 21 days, and maximum calcium accumulation following approximately 8 weeks. The kinetics of mineralization of porcine aortic valve and bovine pericardium are similar. (Reproduced by permission from F. J. Schoen and R. J. Levy, "Pathophysiology of bioprosthetic heart valve calcification," In Biological and Bioprosthetic Valves, E. Bodnar and M. H. Yacoub (eds.), Yorke, New York, 1986, p. 418.)

the earliest mineral deposits in both clinical and experimental BPT are localized to transplanted connective tissue cells, but not extracellular collagen fibers; collagen involvement occurs later. ${ }^{17,19,29,30,31}$ As the implant period increases, cell-associated deposits increase in size and number and dissect among collagen bundles. Analogous to the morphology of clinical valve failures, gross nodules focally obliterate implant architecture and ulcerate through the cuspal surface. ${ }^{5}$ These nodules result from proliferation of nucleation sites, crystal growth, and progressive confluence of diffusely distributed microcrystals.

The earliest events in mineralization of BPT connective tissue cells are hypothesized to result from glutaraldehyde-induced cellular "devitalization" and resulting disruption of cellular calcium regulation., ${ }^{2,20}$ Intact living animal cells have low intracellular free calcium concentrations (approximately $10^{-7} \mathrm{M}$ ), while extracellular free calcium is much higher (approximately $10^{-3} \mathrm{M}$ ), a 10,000-fold gradient across the plasma membrane. In healthy cells, internal calcium is maintained low by energy-requiring metabolic processes, such as plasma membrane-bound $\mathrm{Ca}^{2+}$-ATPase, which uses the energy of ATP hydrolysis to pump $\mathrm{Ca}^{2+}$ out of the cell, and intracellular binding by soluble cytosolic or membrane-bound proteins. Moreover, in membrane-bound organelles such as mitochondria, calcium and phosphorus levels are relatively high, and the organellar and plasma membranes themselves contain considerable phosphorus, largely as phospholipids. These sources of phosphorus are the observed sites of early BPT mineralization. We hypothesized that passive 


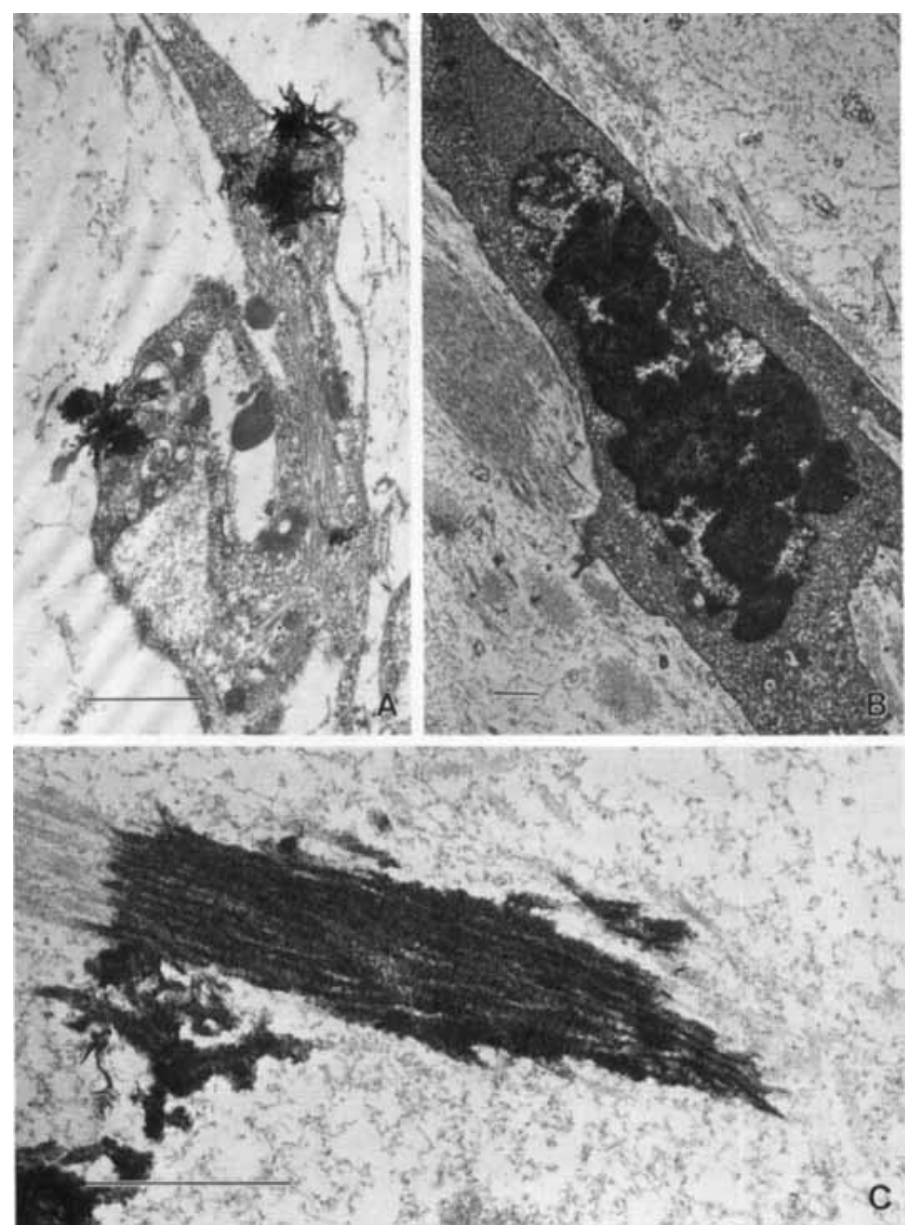

Figure 3. Ultrastructure of calcific deposits in porcine aortic valve tissue implanted subcutaneously in three week old rats. (A) Focal deposits at cell surface and cytoplasm ( $48 \mathrm{~h}$ ). (B) Extensive intranuclear calcification (72 h); (C) Collagen calcification (21 days). Sections stained with uranyl acetate and lead citrate. Bar $=1 \mu \mathrm{m}$. [(A) Reproduced by permission from F.]. Schoen et al., "Bioprosthetic valve failure," In Contemporary Issues In Cardiovascular Pathology, B.F. Waller (ed.), F.A. Davis, Philadelphia, 1988, p. 289. (B) and (C) reproduced by permission from F. J. Schoen et al., "Onset and progression of experimental bioprosthetic heart valve calcification," Lab. Invest., 52, 523 (1985).]

calcium entry probably occurs unimpeded in cells modified by aldehyde crosslinking, mechanisms for calcium removal are no longer functional. ${ }^{20}$ In this model, calcium influx would contribute to apatite formation by reacting with compartmentalized, bound phosphorus. Early crystal nuclei would progressively accumulate additional mineral, eventuating in macroscopic calcific deposits. This sequence is summarized in Figure 5.

In support of the above hypothesis, we have demonstrated, using a newly available technique called electron energy loss spectroscopy (EELS), focally high concentrations of intracellular phosphorus in unimplanted, 

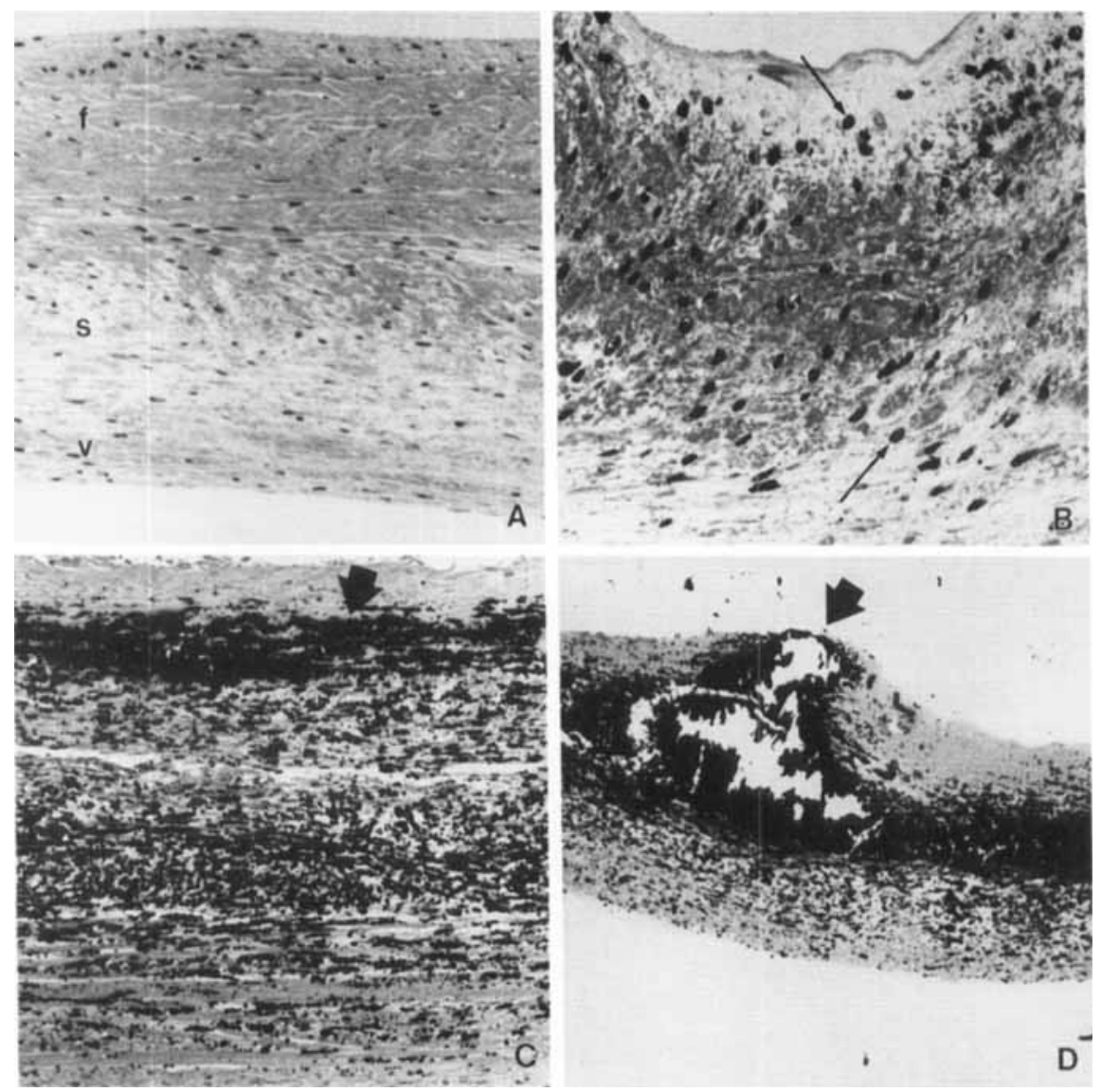

Figure 4. Light microscopic appearance of progressive calcification of porcine aortic valve implanted subcutaneously in 3-week-old rats. (A) unimplanted porcine aortic valve, illustrating layered structure, with fibrosa (f), spongiosa (s), and ventricularis (v). (B) 72-h implant, illustrating initial cell-oriented deposits. (C) 21-day implant demonstrating early nodule formation (arrow). (D) 84-day implant demonstrating ulceration of nodule through cuspal surface (arrow). (A) Stained with hematoxylin and eosin, (B)-(D) stained with von Kossa stain (calcium phosphates black). Original magnifications: (A) $200 \times$, (B) $375 \times$, (C) $200 \times$, (D) $80 \times$. [Reproduced by permission from F. J. Schoen et al., "Onset and progression of experimental bioprosthetic heart valve calcification," Lab. Invest., 52, 523 (1985).]

glutaraldehyde-preserved porcine aortic valve and bovine pericardium. Calcium accumulates in the tissues, with the formation of calcium phosphate deposits at cellular sites, as early as two days following implantation in rats (Fig. 6). ${ }^{32}$

Collagen calcification, commonly noted in calcified clinical retrievals, occurs later in the course of experimental subdermal BPT calcification than cell-oriented mineralization ${ }^{17,20}$; it is unknown whether collagen deposits are related to contiguous cell-oriented mineral deposition, or arise independently. However, since calcification of aldehyde-crosslinked Type I collagen 


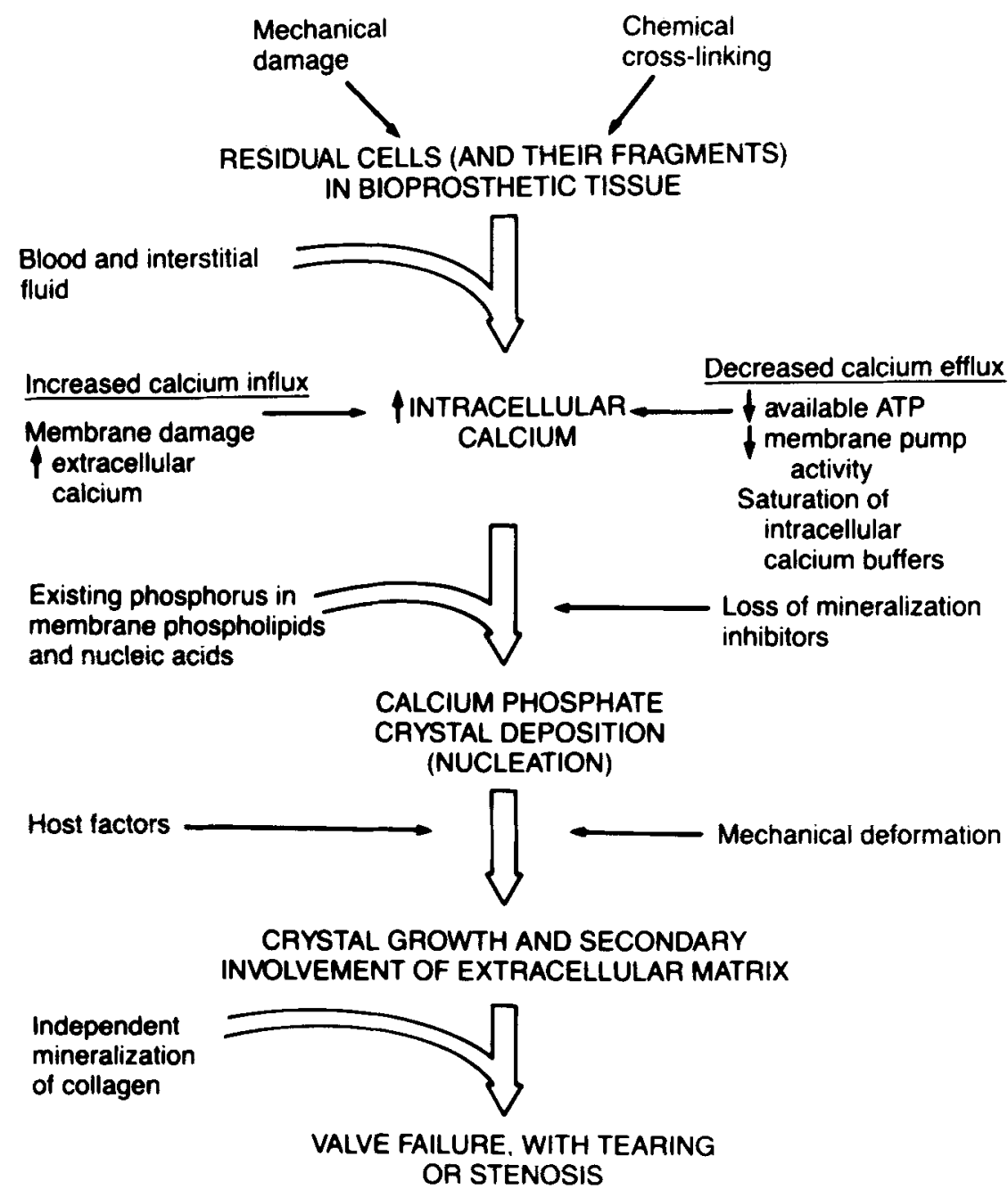

Figure 5. Hypothetical model for calcification of bioprosthetic tissue. This model considers host factors, implant factors, and mechanical damage, relating the initial site of mineral nucleation to increased intracellular calcium in residual cells and cell fragments of bioprosthetic tissue. The ultimate result of calcification is valve failure with tear or stenosis. [Reproduced by permission from F. J. Schoen, Interventional and Surgical Cardiovascular Pathology: Clinical Correlations and Basic Principles, W. B. Saunders, Philadelphia, 1989.]

sponges takes place without associated cell-oriented calcification, calcification of cells and collagen could occur independently. ${ }^{33}$

Similarity of bioprosthetic valve mineralization (and other pathologic calcifications) to physiological mineralization, and the potential role of alkaline phosphatase

Pathological calcification in the "calcific diseases" (e.g., degenerative calcific aortic stenosis, atherosclerosis) and the normal (physiological) calcifica- 


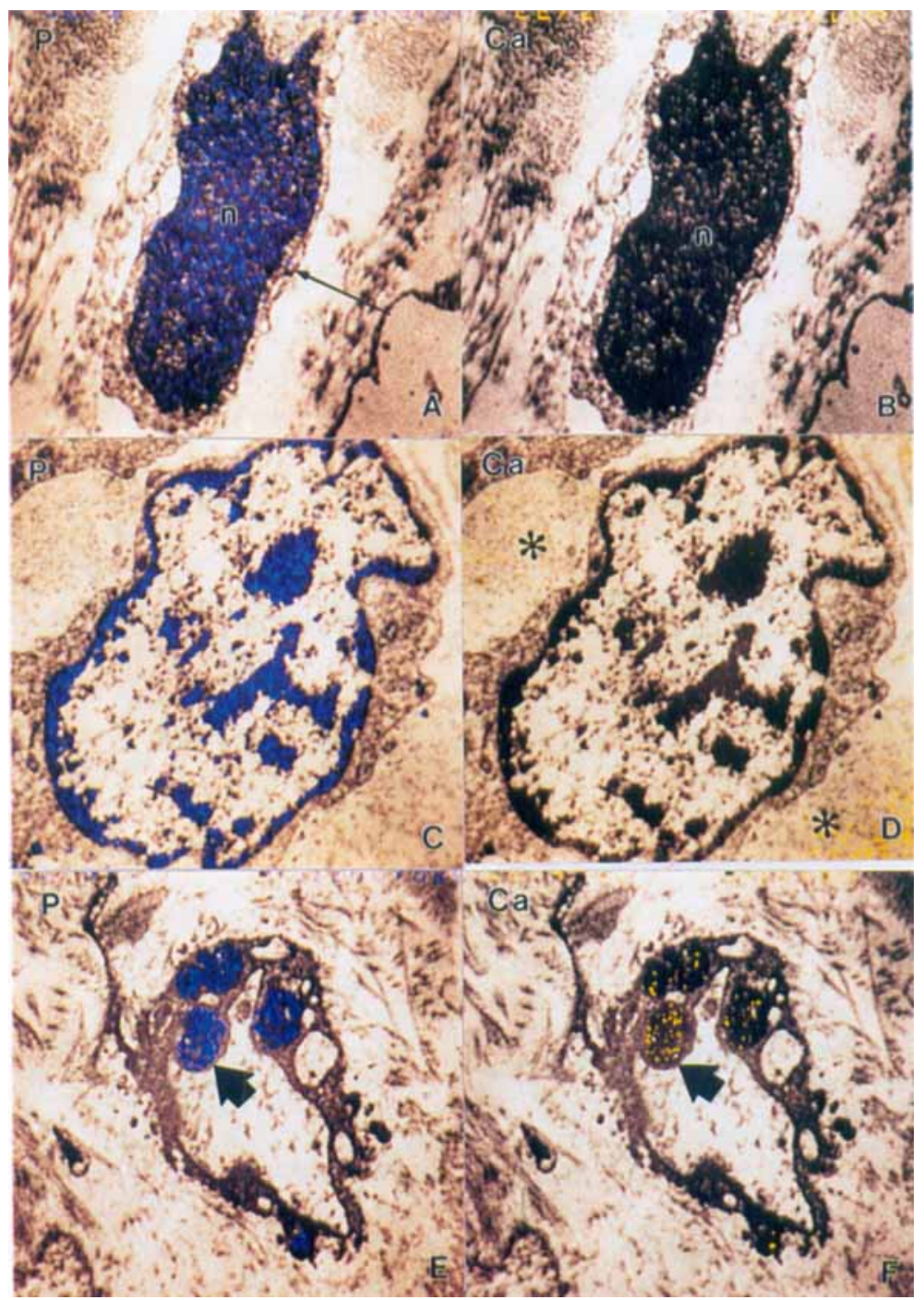

Figure 6. Localization of initial precipitation of apatitic mineral in experimental bioprosthetic valve calcification, visualized by transmission electron microscopy with electron energy loss spectroscopy (EELS). Elemental maps (phosphorus [blue] and calcium [yellow]) of glutaraldehydepretreated porcine aortic valve, produced using the Zeiss EM 902; (A) and (B) unimplanted tissue; (C) and (D) tissue implanted subdermally in the rat for $24 \mathrm{~h}$; and (E) and (F) tissue implanted for $48 \mathrm{~h}$. A single cell is shown in each set of photographs. Phosphorus but not calcium can be demonstrated in the unimplanted tissue ( $A$ and $B$ ), primarily in the nucleus (n) and focally in the cell membrane (arrow). Following $24 \mathrm{~h}$ implantation (C) and (D), there is accumulation of calcium diffusely in the extracellular space (asterisks). Following $48 \mathrm{~h}$ implantation (E) and (F), there is accumulation of calcium in association with the localized phosphorus, to form electrondense, well-defined precipitates (arrows). $(e=150 \mathrm{eV}$ for contrast enhancement of unstained $30-\mathrm{nm}$ sections. Specific energies: calcium $e=$ $320-360 \mathrm{eV}$ [L2, $3=346.4]$, phosphorus $e=110-140 \mathrm{eV}[\mathrm{L} 2,3=132.2]$. Original magnification $10,000 \times$. (Reproduced by permission from C. L. Webb et al.," "Inhibition of mineralization of glutaraldehyde-pretreated bovine pericardium by $\mathrm{AlCl}_{3}$ and other metallic salts in rat subdermal model studies," Am. J. Pathol., in press.) 
tion of skeletal and dental tissues share important features. ${ }^{2,34-36}$ In both, initial mineral deposits are poorly crystalline apatitic mineral, highly insoluble in body fluids at physiological $\mathrm{pH}$. Such crystals are able to proliferate in serum concentrations of calcium and phosphate, with precipitation of new crystals on nuclei provided by initial deposits. In both pathologic and physiologic mineralization, cell and collagen crystal deposits are ultimately present. Moreover, nearly all forms of cell-oriented calcification occur by crystal formation on cell membranes, usually in the form of extracellular vesicles. ${ }^{35,36}$ Mineral initiation in developing bones, in the dentin of teeth, and in the epiphyseal growth plate cartilage of long bones results from the deposition of apatite crystals within and upon extracellular "matrix vesicles," structures that have both a high concentration of calcium-binding acidic phospholipids within their membranes, as well as a high activity of phosphatases, especially alkaline phosphatase (AP). ${ }^{2,35,36}$ Moreover, pathological calcification processes, including calcific degeneration of aged aortic valves ${ }^{37}$ and mineralization in atherosclerotic plaque, ${ }^{38}$ also are associated with matrix vesicle-like cell fragments.

AP-mediated phosphoester hydrolysis has been hypothesized to facilitate mineralization by several possible mechanisms, including increasing regional phosphate concentrations at potential initial calcification sites and degradation of endogenous inhibitors of calcification, such as pyrophosphate and phosphocitrate. ${ }^{36}$ The importance of AP in physiological mineralization is exemplified by a recent demonstration that a genetically defective AP, produced by a missense mutation in the AP genome, causes the grossly defective mineralization typical of the disease hypophosphatasia. ${ }^{39}$

Because bioprosthetic valve mineralization, other pathological cardiovascular calcifications, and physiological mineralization are largely initiated in cell-derived membranous structures, and because AP likely has an important function in mineral nucleation in bone, we hypothesize that AP might contribute to mineralization of BPT. Following glutaraldehyde crosslinking, bovine pericardium retains histochemically demonstrable AP hydrolytic activity localized to the membranous cell remnants known to be the initial sites of mineralization ${ }^{40}$ (Fig. 7). This not only has implications with regard to mechanisms and potential prevention of bioprosthetic tissue calcification, but also refutes the widely held view that all metabolic activities characteristic of viable tissue are destroyed in the fabrication and preimplantation storage of bioprostheses.

Further studies, preliminary to the work described below, indicate that histochemically demonstrable AP is in (a) bovine pericardium pretreated in glutaraldehyde for as long as 82 days, albeit diminished in intensity (despite inability to chemically extract enzyme at this juncture); (b) fresh porcine aortic valve; and (c) glutaraldehyde-pretreated porcine valve implanted 5 months in a sheep. In the latter experiment, the predominant enzyme activity present at explantation appeared to be in a superficial portion of the valve cusp, possibly in adherent cells and/or tissue. These results are summarized in Figure 8. 

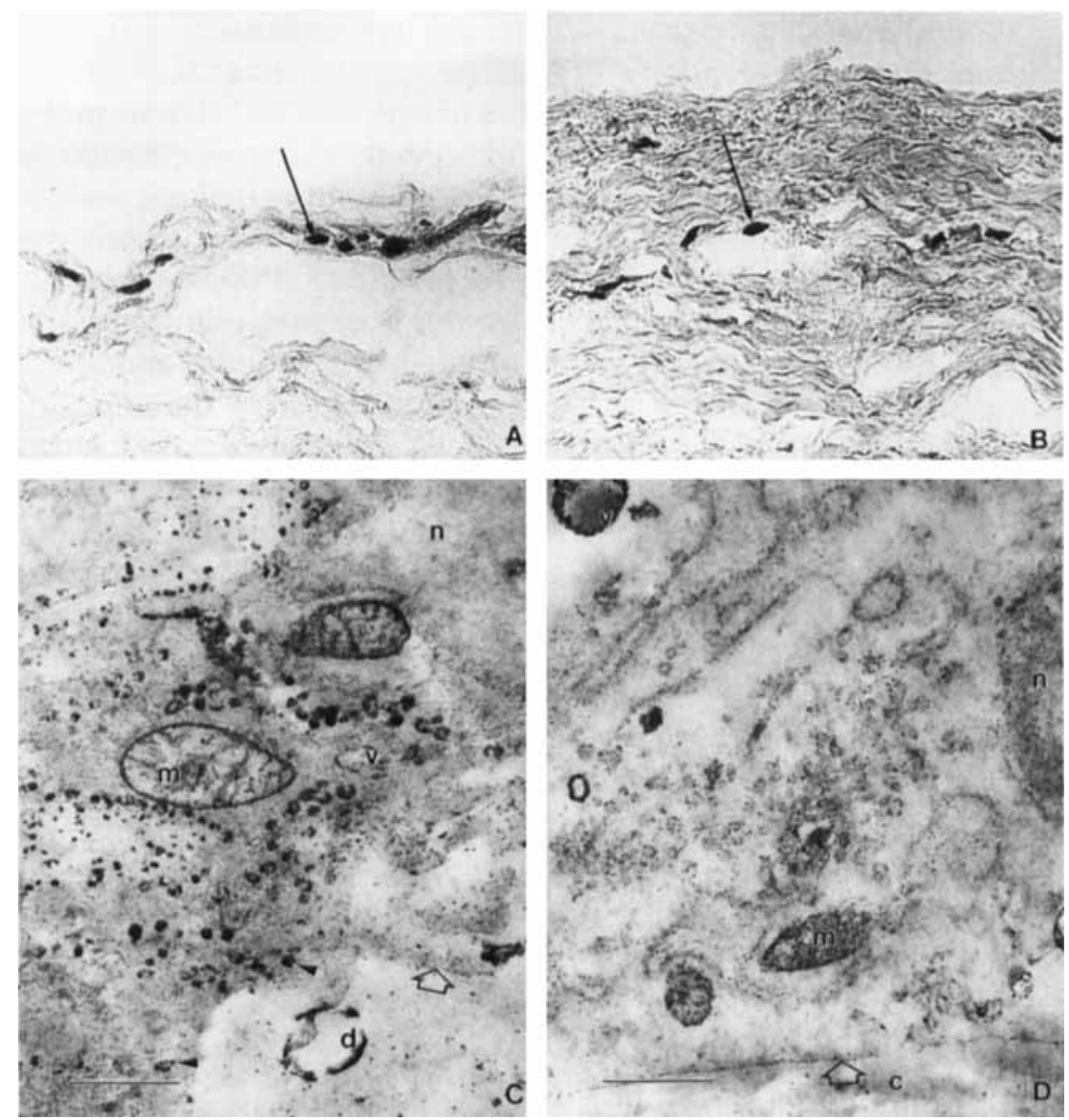

Figure 7. Intrinsic alkaline phosphatase enzyme in bioprosthetic tissue. (A) and (B) Cryomicrotome (frozen) sections of pericardium stained by alkaline phosphatase histochemical method. (A) Untreated (fresh) tissue with staining of cells in the fibrosa (arrow). (B) Glutaraldehyde-treated tissue, demonstrating residual staining of connective tissue cells (arrow). (C) and (D) Ultrastructural demonstration of alkaline phosphatase activity in glutaraldehyde-treated pericardium. (C) Capillary endothelial cell with AP reaction product associated with membranes of plasmalemma vesicles (arrowheads), mitochondria (m), the plasmalemma (open arrow), and intraluminal debris (d). Nucleus (n) is unstained. (D) Fibroblast with activity localized to mitochondria $(\mathrm{m})$, irregular vacuoles $(\mathrm{v})$, and the plasmalemma (open arrow). Nucleus (n) and collagen fibers (c) are unreactive. Original magnifications: (A) $375 \times$, (B) $375 \times$, in (C) and (D) bar $=1.0 \mu \mathrm{m}$. [Reproduced by permission from A.R. Maranto and F. J. Schoen, "Alkaline phosphatase activity of glutaraldehyde-treated bovine pericardium used in bioprosthetic cardiac valves," Circ. Res., 63, 844 (1988).] 

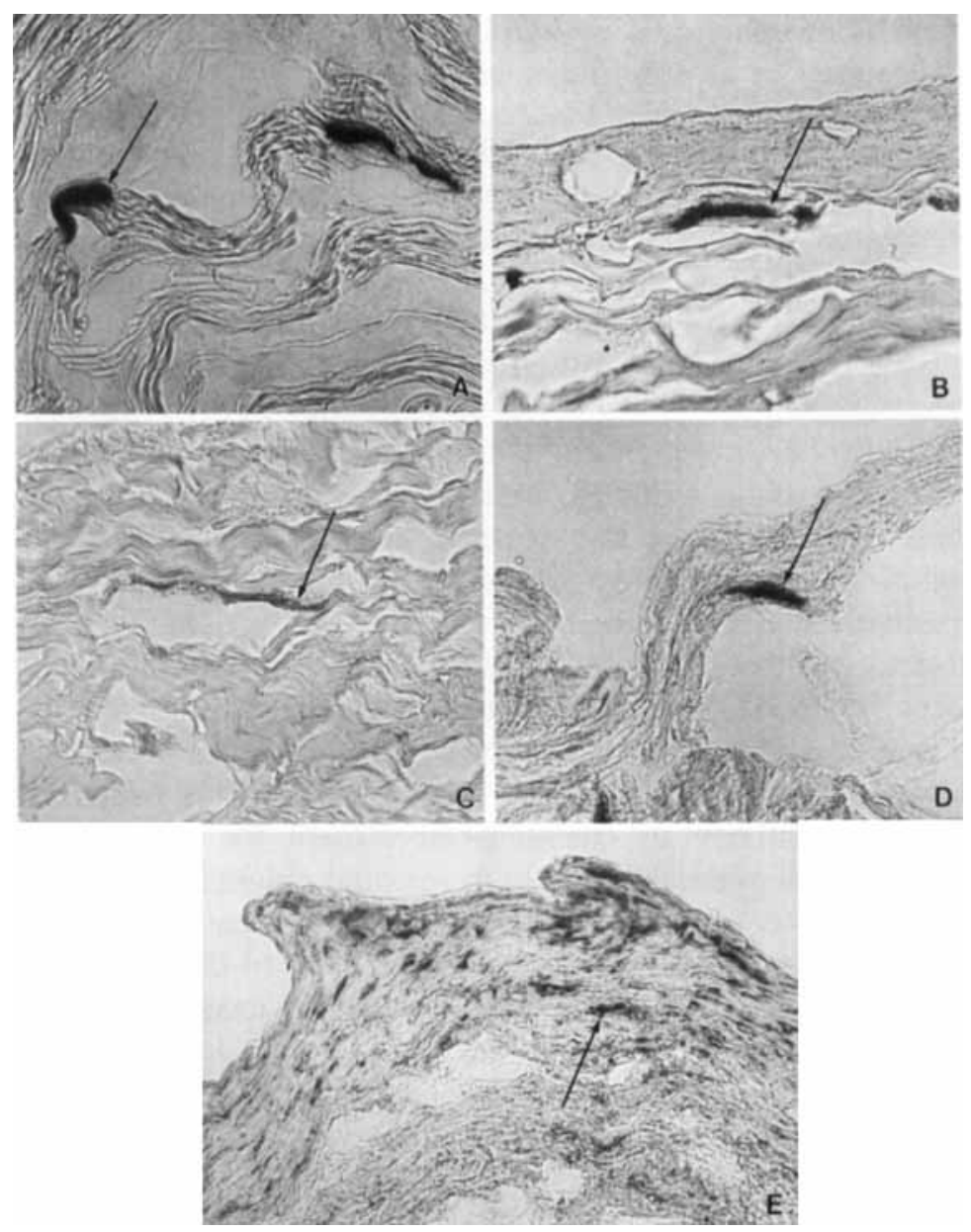

Figure 8. Effect of both glutaraldehyde incubation time and implantation on alkaline phosphatase demonstrated histochemically in cryostat sections of bioprosthetic tissue. Histochemical demonstration of alkaline phosphatase in bovine pericardium (A)-(C) and porcine aortic valve (D) and (E). (A) Fresh bovine pericardium, (B) pericardial tissue incubated for $24 \mathrm{~h}$ in $0.2 \%$ glutaraldehyde, $(\mathrm{C})$ pericardial tissue incubated for 82 days in $0.2 \%$ glutaraldehyde, (D) fresh porcine aortic valve, (E) porcine aortic valve bioprosthesis implanted in sheep for 5 months. Alkaline phosphatase staining of cells (dark reaction product) is evident in the bioprosthetic tissue (arrow in each). However, there is considerably less alkaline phosphatase in the tissue incubated for 82 days $(C)$, in which the staining is faint (arrow), relative to that in the fresh tissue (A). Moreover, alkaline phosphatase accumulated extrinsically in the tissue removed during function (E) suggests that activity arises, at least in part, from recipient enzyme. Original magnification $(A)-(E) 375 \times$. 


\section{Inhibition of bioprosthetic tissue mineralization: Alkaline phosphatase neutralization may be an important mechanism}

Strategies for prevention of BPT mineralization involve modifications of either the implant or its local environment. Experimental studies thus far have concentrated on either cuspal pretreatment with detergents or diphosphonate compounds, or systemic or local therapy of the host with diphosphonates (Table II) (reviewed in Refs. 2, 6-8). Diphosphonates, used to treat some metabolic bone diseases, are synthetic pyrophosphate analogs that probably inhibit calcification by binding to developing hydroxyapatite crystals, thereby restricting crystal growth. ${ }^{41}$ Daily subcutaneous injections of ethanehydroxy diphosphonate (EHDP) nearly completely inhibit calcification of subcutaneous BPT implants, but cause retardation of somatic growth and generalized disruption of bone development in the recipient rat. ${ }^{42,43}$ However, local controlled-release administration of EHDP by osmotic minipump or controlled-drug-release matrices prevents calcification without adverse systemic effects. ${ }^{42,44}$ Subsequent studies have been directed toward optimizing controlled release of diphosphonates for BPT mineralization inhibition. ${ }^{45-51}$ In addition, near-complete inhibition of mineralization has been achieved by enhancing the efficiency of cuspal pretreatment by covalent linkage of aminopropane diphosphonate (APDP) to residual aldehyde groups in the glutaraldehyde-pretreated $\mathrm{BPT}^{52,53}$ Although pretreatment in sodium dodecyl sulfate (SDS) also significantly inhibits calcification of BPT implanted subcutaneously in rats, results in experimental circulatory models have been inconsistent (reviewed in Refs. 2, 6-8).

Preincubation of glutaraldehyde pretreated BPT in aqueous solutions of either $\mathrm{AlCl}_{3}$ or $\mathrm{FeCl}_{3}$ inhibits calcification in rat subdermal studies. ${ }^{32,54}$ The ra-

TABLE II

Inhibition of Calcification of Subcutaneously Implanted Bioprosthetic Tissue by Host and Implant Modification

\begin{tabular}{lcccc}
\hline \multicolumn{1}{c}{$\begin{array}{c}\text { Experimental } \\
\text { Condition }\end{array}$} & $\begin{array}{c}\text { Duration } \\
\text { (days) }\end{array}$ & $\begin{array}{c}\text { Calcium } \\
(\mu \mathrm{g} / \mathrm{mg})\end{array}$ & $\begin{array}{c}\text { Inhibition } \\
(\%)\end{array}$ & Reference \\
\hline Control & 14 & $135 \pm 6$ & - & 42 \\
Control & 21 & $155 \pm 4$ & - & 42 \\
Control & 84 & $219 \pm 14$ & - & 44 \\
EHDP, systemic ${ }^{a}$ & 21 & $4 \pm 1$ & 97 & 42 \\
EHDP, local & 14 & $4 \pm 1$ & 97 & 42 \\
EHDP, controlled release polymer & 84 & $16 \pm 6$ & 93 & 44 \\
APDP, cuspal pretreatment & 21 & $24 \pm 7$ & 84 & 42 \\
EHDP, cuspal pretreatment & 21 & $114 \pm 10$ & 24 & 42 \\
SDS, cuspal pretreatment & 21 & $19 \pm 4$ & 84 & $*$ \\
\hline
\end{tabular}

Mean \pm SEM; EHDP = ethanehydroxy diphosphonate; APDP = aminopropane diphosphonate; SDS = sodium dodecyl sulfate.

${ }^{a} \mathrm{EHDP}=$ associated bone toxicity noted.

*Unpublished data (R. J. Levy, J.T. Levy, F. J. Schoen).

Reproduced by permission from F. J. Schoen and R. J. Levy, "Pathophysiology of bioprosthetic heart valve calcification," In Biological and Bioprosthetic Valves, E. Bodnar and M. H. Yacoub (eds.), Yorke, New York, 1986, p. 418. 
tionale for these experiments was based on observations by others that both aluminum and iron can be contributory to osteodystrophy in patients on chronic hemodialysis. ${ }^{55-58}$ The mechanism of action of iron and aluminum inhibition of BPT calcification is presently uncertain. ${ }^{59-62}$ However, our studies using special staining methods (for $\mathrm{Al}$ and Fe) and EELS suggest that mitigation of mineralization derives from the association of aluminum or iron with devitalized cells in glutaraldehyde-pretreated BPT, the sites of initial calcification (Figs. 9, 10). ${ }^{32}$ As AP is also associated with these sites, and because AP activity has been shown to be inhibited by metallic ions, we hypothesize that

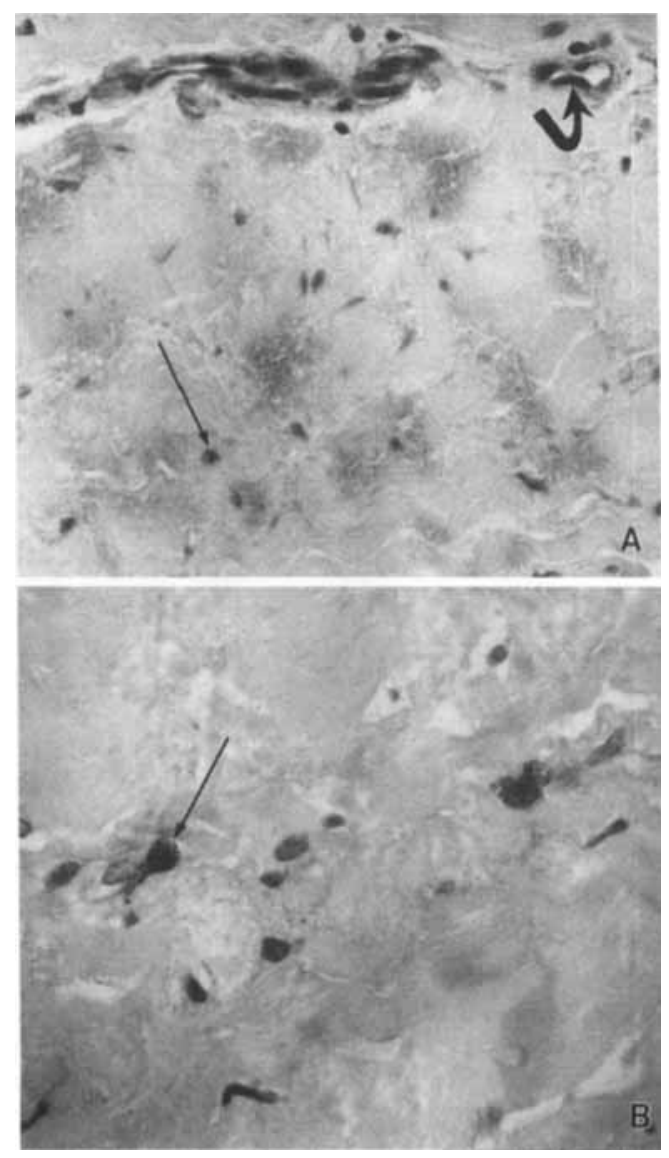

Figure 9. Histologic demonstration, with special stains, of aluminum and iron localization in glutaraldehyde-pretreated bovine pericardium, unimplanted and implanted, respectively. (A) Unimplanted tissue pretreated in $0.01 \mathrm{M} \mathrm{AlCl}_{3}$, illustrating cellular localization of aluminum in both interstitial connective tissue cells (arrow) and vascular wall cells, including endothelium (curved arrow). (B) Pericardium incubated in $0.01 \mathrm{M} \mathrm{FeCl}_{3}$ and implanted for 60 days. Following implantation, persistent staining for iron is present in connective tissue cells (arrow). (A) stained using the Aluminon technique for aluminum. (B) stained with Prussian blue technique for iron. Original magnification: (A) $375 \times$, (B) $600 \times$. 


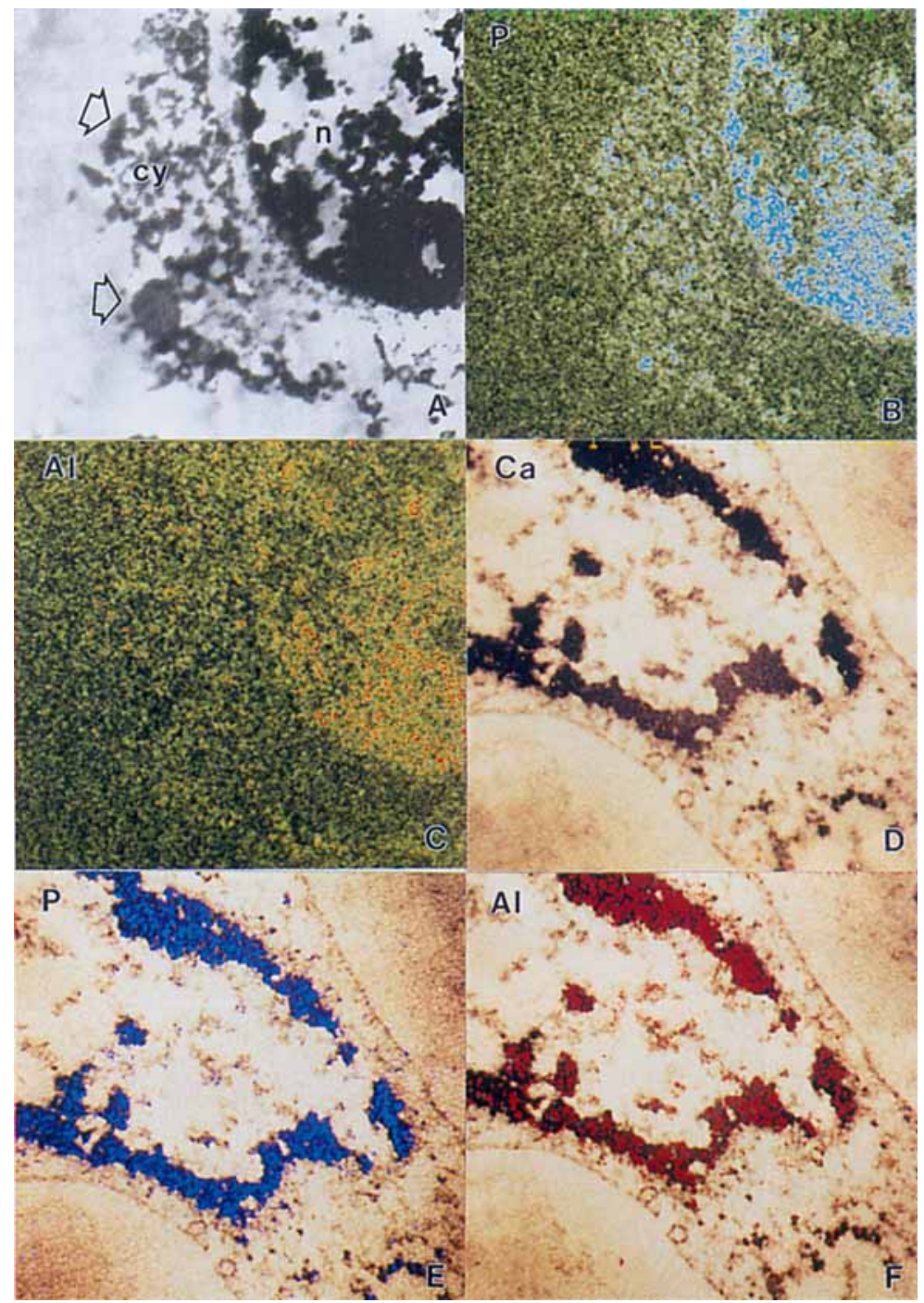

Figure 10. Cellular localization and effect on calcification of aluminum in bioprosthetic tissue, following incubation in $0.1 \mathrm{M} \mathrm{AlCl}_{3}$, in both unimplanted tissue and tissue implanted for 21 days, using transmission electron microscopy with electron energy loss spectroscopy (EELS). (A), (B), and (C) Ultrastructural morphology, map of phosphorus (blue) and map of aluminum (red/orange), respectively, of a cell in the unimplanted tissue. The nucleus (n), cytoplasm (Cy), and limiting cell membrane (open arrows) are demonstrated in (A). (D), (E), and (F) show a cell from tissue which was incubated in $0.1 \mathrm{M} \mathrm{AlCl}_{3}$ and subsequently implanted subdermally in the rat for 21 days. The upper row (unimplanted tissue) shows phosphorus and aluminum localized to identical sites in the cell, predominantly the nucleus and cytoplasmic membranes. The lower row (D), (E), and following implantation, $(F)$, demonstrate that aluminum not only remains localized in the tissue to the same sites as phosphorus, but also that the accumulation of calcium (yellow) at these sites is minimal. Specific energy loss levels: aluminum $e=60-75 \mathrm{eV}(\mathrm{L} 2,3=73.1)$, phosphorus $e=110-140 \mathrm{eV}(\mathrm{L} 2,3=$ $132.2)$, and calcium $e=320-360 \mathrm{eV}(\mathrm{L} 2,3=346.4)$. Original magnification $10,000 \times$. (Reproduced by permission from C. L. Webb et al., "Inhibition of mineralization of glutaraldehyde-pretreated bovine pericardium by $\mathrm{AlCl}_{3}$ and other metallic salts in rat subdermal model studies," Am. J. Pathol., in press.) 
aluminum or iron or both inhibit calcification through neutralization of alkaline phosphatase, at least in part. The above hypotheses form the basis for the investigation described below.

\section{EXPERIMENTAL}

\section{Materials}

Electron microscopy grade glutaraldehyde was obtained as an $8 \%$ aqueous solution (Polyscience, Warrington, PA). The buffer used for crosslinking was prepared with $0.05 \mathrm{M} \mathrm{N}$-2-hydroxyethylpiperazine- $N^{\prime}$-2-ethanesulfonic acid (HEPES, Sigma Chemical, St. Louis, MO) with $0.1 \mathrm{M} \mathrm{NaCl}$ (J.T. Baker, Inc., Phillipsburg, NJ). Reagent grade $\mathrm{FeCl}_{3}, \mathrm{AlCl}_{3}$, and $\mathrm{MgSO}_{4}$ were obtained from Mallinckrodt (Paris, KY). 2-Amino-2-methyl-1-propanol (2A2MIP), secbutanol, $p$-nitrophenyl phosphate (pnpp), and p-nitrophenol (pnp) were also obtained from Sigma.

Parietal pericardium was obtained at slaughter from mature bovines and placed in $0.6 \%$ glutaraldehyde in $0.05 \mathrm{M}$ HEPES buffer ( $\mathrm{pH} 7.4$ ). After $24 \mathrm{~h}$, the glutaraldehyde pretreated bovine pericardium (GPBP) was transferred to $0.2 \%$ glutaraldehyde in the same buffer and stored at $4^{\circ} \mathrm{C}$ for 1 to 4 weeks prior to use. ${ }^{19,20,28}$ Extractable AP enzymatic activity (see below) was assayed after $96 \mathrm{~h}$ in glutaraldehyde, and then once weekly after 8 weeks of storage.

\section{Implant and explant methods}

All animals received humane care in compliance with established guidelines, as approved by the Animal Use Committee at the University of Michigan, Ann Arbor, MI. ${ }^{63,64}$ Three-week-old (50-60 g) male Sprague-Dawley rats (CD strain; Charles River Laboratories, Burlington, MA) used for the temporal study were fed Rodent Laboratory Chow (Purina Mills, Inc., St. Louis, $\mathrm{MO}$ ). The rats were anesthetized by an intramuscular injection of xylazine and ketamine hydrochloride. Ten subdermal pouches at least $2 \mathrm{~cm}$ apart were dissected on each rat ( 6 ventral, 4 dorsal). GPBP specimens were cut into squares approximately $1 \mathrm{~cm} \times 1 \mathrm{~cm}$ and washed in distilled water to remove residual glutaraldehyde. One GPBP specimen was implanted in each pouch and the wound stapled.

Three rats were sacrificed by $\mathrm{CO}_{2}$ asphyxiation at $24,36,48$, and $72 \mathrm{~h}$, and $7,14,21,30,60,90$, and 120 days. Explanted GPBP were analyzed for calcium and AP (see below). A representative portion of each GPBP explant was placed immediately in Karnovsky's fixative ${ }^{65}$ at $\mathrm{pH} 7.2$ for morphological analysis, and a piece at 24 and $72 \mathrm{~h}$ and 21 days was frozen for histochemistry. Remaining GPBP specimens from each rat were pooled, exhaustively washed in saline and distilled water, lyophilized overnight, minced into a course powder, and frozen $\left(-20^{\circ} \mathrm{C}\right)$. 


\section{Additional GPBP implants with inhibitors}

Additional implants were done in which GPBP was preincubated in aqueous solutions of either $\mathrm{FeCl}_{3}$ or $\mathrm{AlCl}_{3}$ to assess the effects on $\mathrm{AP}$ activity. We have previously shown that concentrations below $0.001 \mathrm{M}$ for $\mathrm{AlCl}_{3}$ and $0.0001 \mathrm{M}$ for $\mathrm{FeCl}_{3}$ have a minimal effect on GPBP calcification in the rat subdermal model. ${ }^{32}$ Thus, GPBP specimens were preincubated in either $0.1 \mathrm{M}$ or $0.00001 \mathrm{M} \mathrm{AlCl}_{3}$, or $0.1 \mathrm{M}$ or $0.00001 \mathrm{M} \mathrm{FeCl}_{3}$, for $24 \mathrm{~h}$ at $25^{\circ} \mathrm{C}$, and implanted as above. Implants were retrieved 21 days after implantation.

\section{Extraction and analysis of alkaline phosphatase (AP)}

Samples $(25-30 \mathrm{mg})$ of the explanted freeze-dried and powdered GPBP tissue were homogenized with a mortar and pestle using $1.0 \mathrm{~mL}$ sec-butanol and $2.0 \mathrm{~mL}$ distilled water. The liquid was removed, and the homogenization and extraction in water and butanol was repeated twice. Extracts were pooled and centrifuged for $10 \mathrm{~min}$ at $1500 \mathrm{~g}$. The aqueous layer was removed and the protein concentration determined by molybdenum complexation using human serum albumin as a standard. ${ }^{66}$ AP extraction procedures were also done on samples of fresh bovine pericardium, and unimplanted GPBP samples preincubated in glutaraldehyde for durations ranging from $24 \mathrm{~h}$ to 8 weeks.

The assay for AP was based on the enzymatic hydrolysis of the substrate, p-nitrophenyl phosphate to $p$-nitrophenol, ${ }^{67}$ which was measured quantitatively using visible light spectroscopy at $405 \mathrm{~nm}$. The buffer used for the enzymatic reaction was composed of $1.07 \mathrm{nM} \mathrm{MgSO}_{4}$ in $0.964 \mathrm{M}$ 2-amino-2methyl-l-propanol (2A2M1P; Sigma) adjusted to $\mathrm{pH} 10.4$. The substrate was prepared at a concentration of $150 \mathrm{nM}$ in distilled water. One hundred microliters of the extracted enzyme solution was added to $2.86 \mathrm{~mL} 2 \mathrm{~A} 2 \mathrm{M} 1 \mathrm{P}$. This was allowed to incubate in a $37^{\circ} \mathrm{C}$ waterbath prior to the addition of substrate. While this was vortexing, $40 \mu \mathrm{L}$ substrate were added and the reaction mixture was placed immediately in a constant temperature-jacketed cuvette holder (Perkin Elmer, Model C 550-0108; Norwalk, CT) at $37^{\circ} \mathrm{C}$. Absorbance was measured using a Lambda 3B Spectrophotometer (Perkin Elmer). Background tubes consisting of substrate and buffer were used to correct for any autohydrolysis of the substrate. The spectrophotometer was linked to an Equity I computer (Epson Corporation, Model Q501A, Nagano, Japan) via an RS232C Interface (Perkin Elmer, Model C 618-0340). A simple program was developed to record the absorbance and time every $20 \mathrm{~s}$ for a duration of $5 \mathrm{~min}$. By altering the amount of substrate and maintaining the total assay volume at $3.0 \mathrm{~mL}$, substrate concentrations were varied from 1 to $10 \mathrm{nM}$. A standard curve of pnp (Sigma) was prepared with which to compare the absorbances and ranged from 0 to $70 \mu \mathrm{M}$. The slope of the linear portion of the absorbance vs. time curve provided a rate of formation which, when divided by the protein concentration, gave activity in $\mathrm{nm} \mathrm{pnp} / \mathrm{min} / \mathrm{mg}$ protein. 


\section{Calcium analysis}

For each specimen, samples $(3-5 \mathrm{mg})$ of the GPBP freeze-dried powder preparation were hydrolyzed in $6 \mathrm{~N} \mathrm{HCl} \mathrm{(J.T.} \mathrm{Baker} \mathrm{Chemical} \mathrm{Co.,} \mathrm{Phillips-}$ burg, NJ) as previously described, ${ }^{17,19,20,28}$ and assayed for calcium using atomic absorption spectroscopy.

\section{Enzyme histochemistry}

For morphologic demonstration of AP, $10-\mu \mathrm{m}$-thick sections of untreated and GPBP were cut with a cryomicrotome, mounted on glass slides, and airdried at room temperature. Sections were incubated at $37^{\circ} \mathrm{C}$ for $30 \mathrm{~min}$ in a medium for AP modified from Gomori ${ }^{68}$ containing $50 \mathrm{~mL}$ of $5 \mathrm{mM} \mathrm{MgCl}_{2}$ in distilled water, $1 \mathrm{~mL}$ Napthol AS-MX phosphate in pH 10.5 buffer (Sigma), and $25 \mathrm{mg}$ Fast Red TR or Fast Blue RR (Sigma). ${ }^{40}$ Following incubation, sections were rinsed, counterstained, and mounted.

\section{RESULTS}

Alkaline phosphatase activity was reproducibly extractable from fresh bovine pericardium (30.4 $\pm 6.8 \mathrm{~nm} \mathrm{pnpp} / \mathrm{min} / \mathrm{mg}$ protein), but was not detectable chemically in bovine pericardium after glutaraldehyde fixation for as little as $24 \mathrm{~h}$. Recall, however, that enzyme can be demonstrated histochemically following 82 days incubation of bovine pericardium in glutaraldehyde (Fig. 8). Moreover, AP enzymatic activity accumulated rapidly within 48 to $72 \mathrm{~h}$ following subdermal implantation of GPBP into rats (Fig. 11). Extractable AP activity rose sharply to a peak at $72 \mathrm{~h}$, then declined to near baseline levels by 21 days. Figure 11 also demonstrates, as in previous studies, that onset of calcification could be detected between 48 and $72 \mathrm{~h}$. Mineral deposition progressed to maximal bulk mineral accumulation at 120 days, when AP activity was at a reduced and stable level. Thus, the maximal AP activity correlated with the onset of mineralization, but calcification progressed despite stable or falling AP levels.

Histochemical studies revealed that 24- and 72-h explants have intense AP activity adsorbed into and near the surface of the GPBP, likely associated, at least in part, with host cells adhering to the surface of the implant (Fig. 12). In general, enzymatic staining in explants was not associated with preexisting intrinsic cuspal cells. This is in marked contrast to our reported morphologic studies utilizing light and electron microscopic enzyme-specific histochemistry which demonstrated AP activity localized exclusively to the devitalized intrinsic GPBP cells, which was qualitatively comparable to the AP activity seen in the microscopy studies of fresh bovine pericardium (recall Fig. 7). By 21 days following implantation, at which time AP activity had declined (Fig. 11), histochemically demonstrable AP was also qualita- 


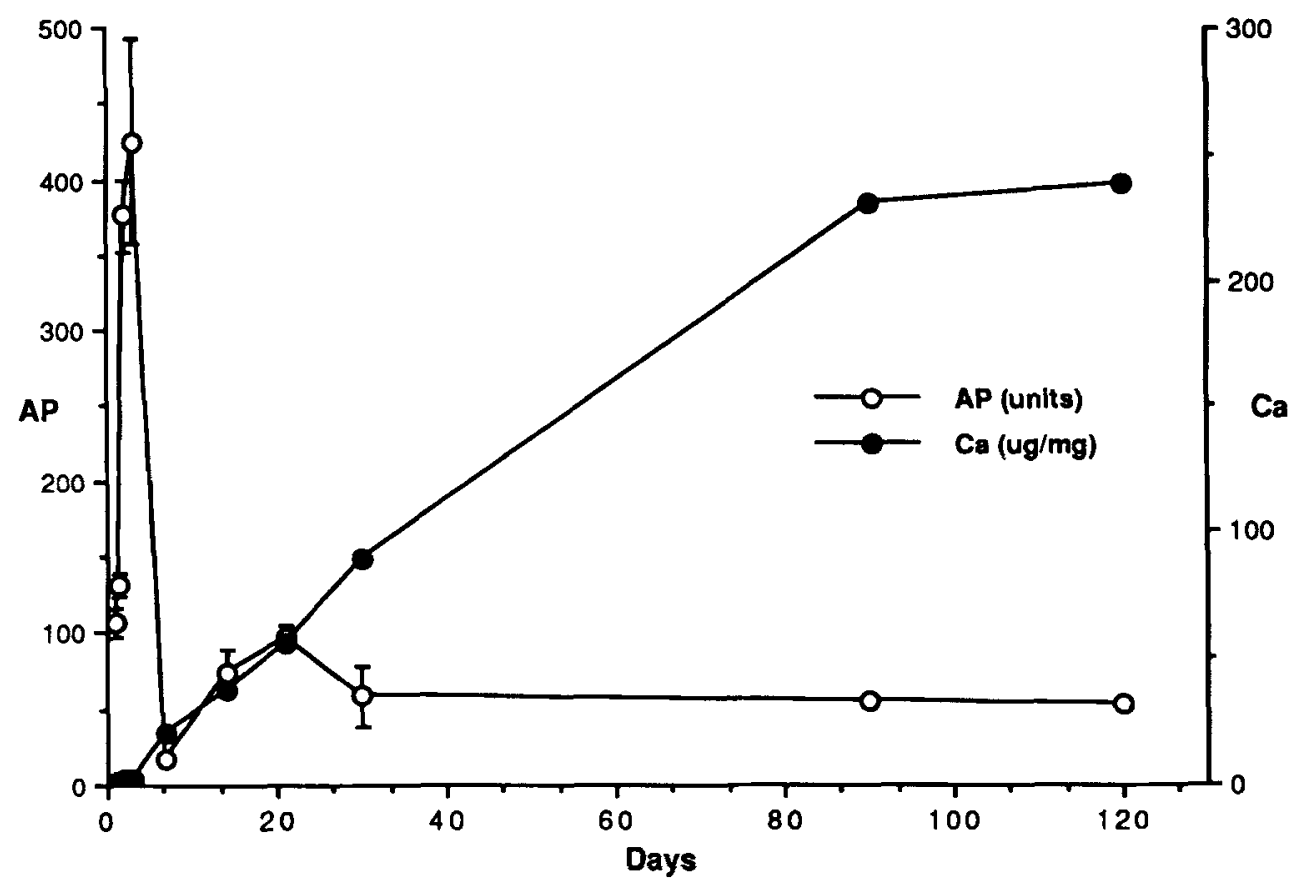

Figure 11. Alkaline phosphatase activity (nm $\mathrm{pnpp} / \mathrm{mg}$ protein $/ \mathrm{min}$ ) and accumulation of calcium $(\mu \mathrm{g} / \mathrm{mg})$ in implants removed at various times from the rat subdermal model. Alkaline phosphatase activity rises sharply to a maximum at $72 \mathrm{~h}$ and then returns to near baseline levels following approximately 4 weeks. Calcification begins in several days and continues to rise to a plateau level. Data shown as means with standard error bars.

tively much less intense, though visible, at the cuspal surface. Correlation of chemical and morphological results is summarized in Table III.

Explant analyses of GPBP pretreated in either $\mathrm{AlCl}_{3}$ or $\mathrm{FeCl}_{3}$ revealed that the level of extractable AP activity was markedly reduced by preincubation concentrations $(0.1 \mathrm{M})$ of these salts sufficient to suppress calcification (Fig. 13). Suppression of AP activity by $0.1 \mathrm{M} \mathrm{FeCl}_{3}$ preincubation (to $<10 \%$ of original) was more profound than that noted with the same concentration of $\mathrm{AlCl}_{3}$ (which reduced AP to approximately $25 \%$ of original). Nevertheless, the extent of inhibition of calcification was comparable for incubations in $0.1 \mathrm{M} \mathrm{FeCl}_{3}$ and $0.1 \mathrm{M} \mathrm{AlCl}_{3}$. Reduction in extractible AP activity and inhibition of calcification correlated with loss of histochemically demonstrable enzyme activity in the $0.1 \mathrm{M} \mathrm{AlCl}_{3}$ GPBP (Fig. 14). More dilute preincubations, in either $0.00001 \mathrm{AlCl}_{3}$ or $0.00001 \mathrm{M} \mathrm{FeCl}_{3}$, did not significantly inhibit calcification, although these preincubations did mildly reduce the level of AP activity compared to control (see Fig. 13).

\section{DISCUSSION}

The present study has two primary results: (a) concurrent with the onset of mineralization of bioprosthetic tissue, AP content sharply increases; the 

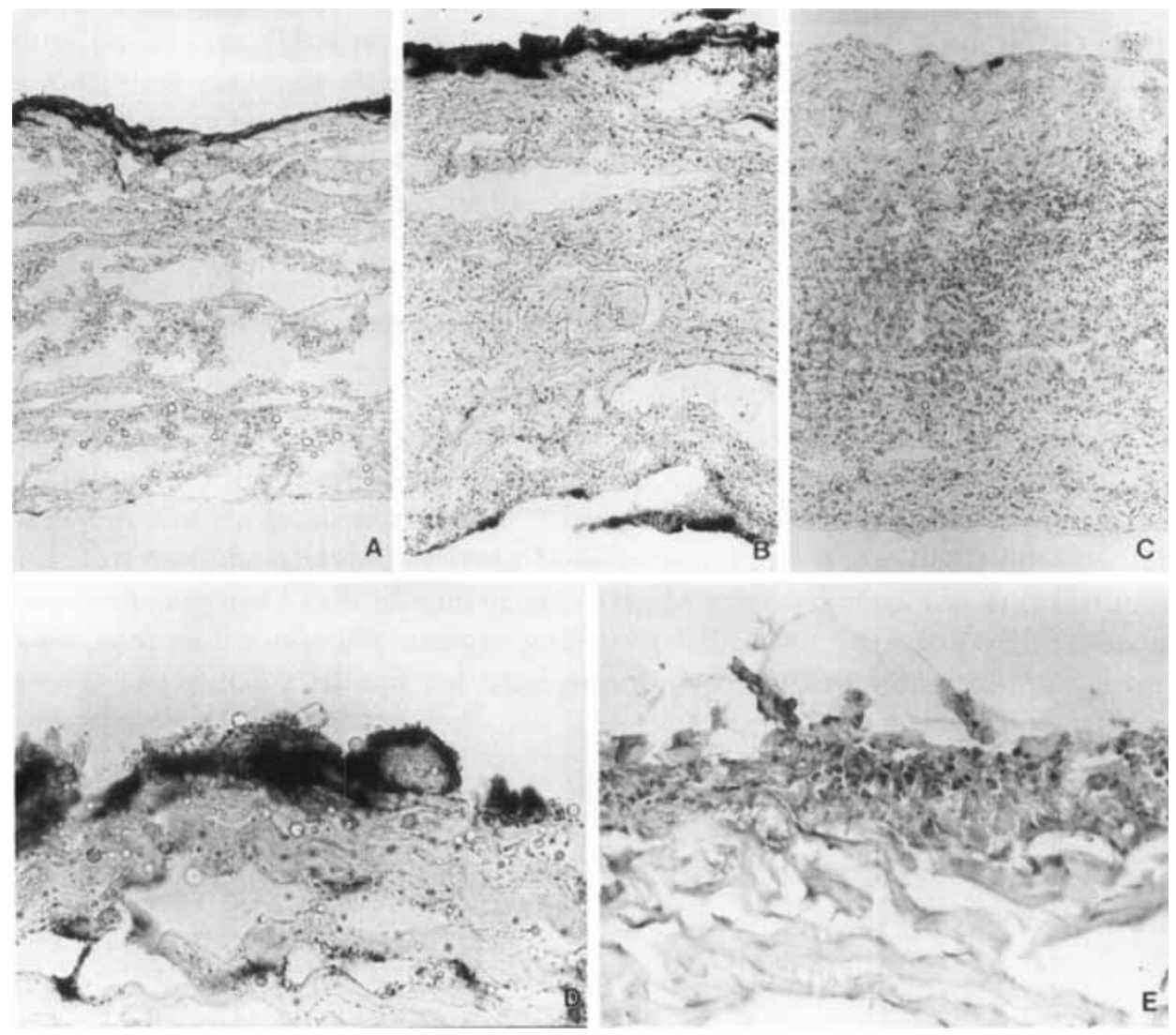

Figure 12. Histochemical demonstration of alkaline phosphatase following implantation of glutaraldehyde-pretreated bovine pericardium. (A) $24 \mathrm{~h},(\mathrm{~B}) 72 \mathrm{~h}$, (C) 21 days. Staining at the surface of the tissue is noted, with the highest intensity in (B), the 72-h implant. (D) High-power photomicrograph of surface accumulation of alkaline phosphatase activity following $72 \mathrm{~h}$. (E) High-power photomicrograph of area of most intense staining in (B) and (D) (72-h explant) demonstrating polymorphonuclear and mononuclear inflammatory cells, derived from the recipient, at the surface of the tissue. (A)-(D) Alkaline phosphatase histochemical stain, (E) hematoxylin and eosin. Cryostat sections. Original magnifications: (A)(C) $140 \times$; (D); (E) $375 \times$.

TABLE III

Correlation of Chemical and Morphological Assays for Alkaline Phosphatase in Subcutaneously Implanted Bioprosthetic Tissue in Rats

\begin{tabular}{cccc}
\hline Time (days) & AP (Enz Units) & AP (Cyto) & Ca $++(\mu \mathrm{g} / \mathrm{mg})$ \\
\hline 0 & 0 & ++ & $1.1 \pm 0.1$ \\
1 & $107 \pm 10$ & +++ & $1.3 \pm 0.4$ \\
3 & $424 \pm 67$ & ++++ & $2.2 \pm 0.3$ \\
21 & $96.8 \pm 6.9$ & + & $56.8 \pm 3.1$ \\
120 & $52.4 \pm 2.7$ & ND & $239 \pm 20$ \\
\hline
\end{tabular}

Mean \pm SEM; $+=$ mild, $++=$ moderate, $+++=$ prominent,$++++=$ most prominent; $\mathrm{ND}=$ not done. 
enhanced activity is localized to the tissue surface, probably associated with inflammatory cells, thereby augmenting the intrinsic enzyme activity we previously described ${ }^{40}$; and (b) intrinsic alkaline phosphatase is neutralized by incubations of bioprosthetic tissue in $\mathrm{AlCl}_{3}$ and $\mathrm{FeCl}_{3}$, treatments which we have shown to markedly reduce mineralization. 32,54

\section{Alkaline phosphatase and the mechanism of bioprosthetic tissue calcification}

Calcification of bioprosthetic tissue is initiated in association with devitalized cellular structures, a process analogous to the normal mineralization of matrix vesicles noted in skeletal tissues. ${ }^{36,69-71}$ Matrix vesicles are cell-derived, 100-200-nm-diameter, membrane-invested particles, ideally adapted to serve as initial sites of mineralization. Matrix vesicle membranes have phosphatases capable of hydrolyzing naturally occurring organic phosphoesters (e.g., ATP and pyrophosphate) to $\mathrm{PO}_{4}$ (orthophosphate for use in calcium-phosphate

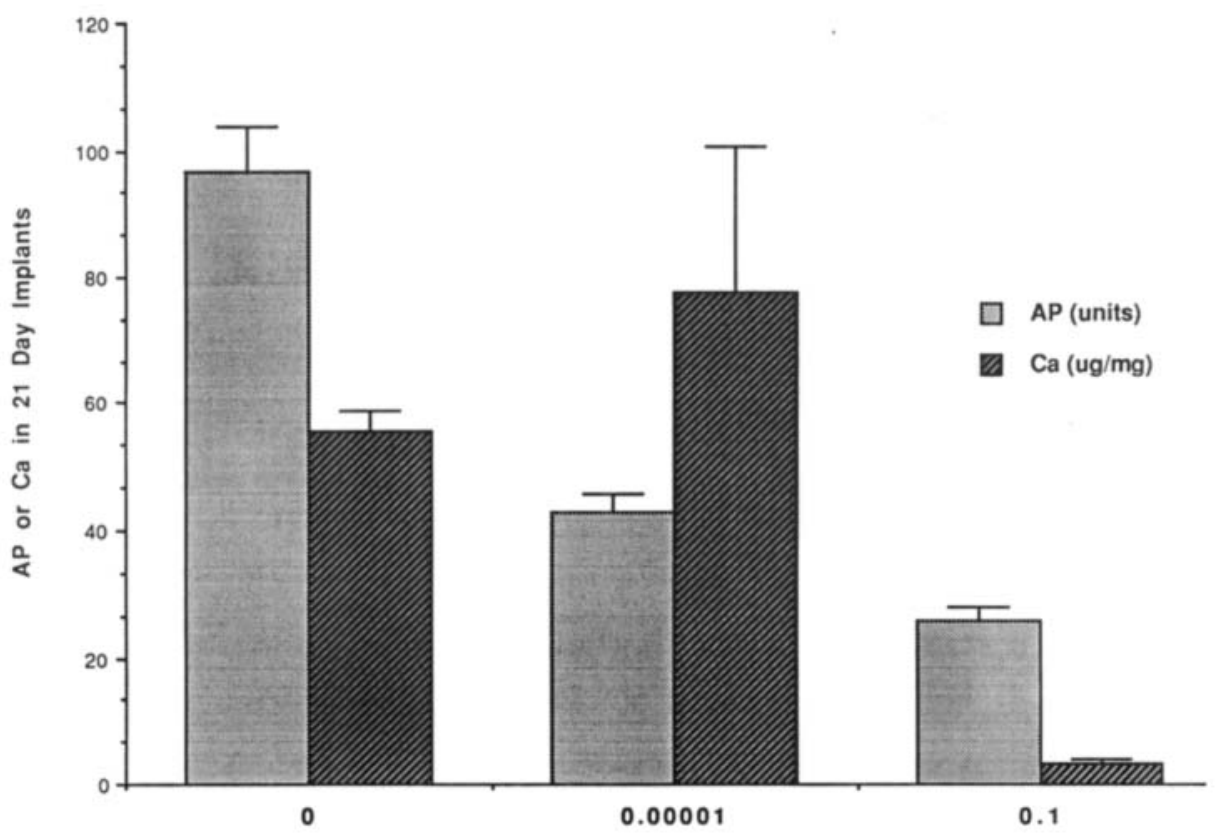

Aluminum Chloride Conc. (M)

(A)

Figure 13. Inhibition of calcification of glutaraldehyde pretreated bovine pericardium in rat subdermal implant studies (21 days) by preincubation in either aluminum chloride (A) or ferric chloride (B). Comparisons of alkaline phosphatase activity ( $\mathrm{nm}$ pnpp/mg protein/minute) and calcium levels $(\mu \mathrm{g} / \mathrm{mg})$. Alkaline phophatase activity is markedly diminished by implant pretreatment, correlating with the inhibition of mineralization. Data shown as means with standard error bars. 


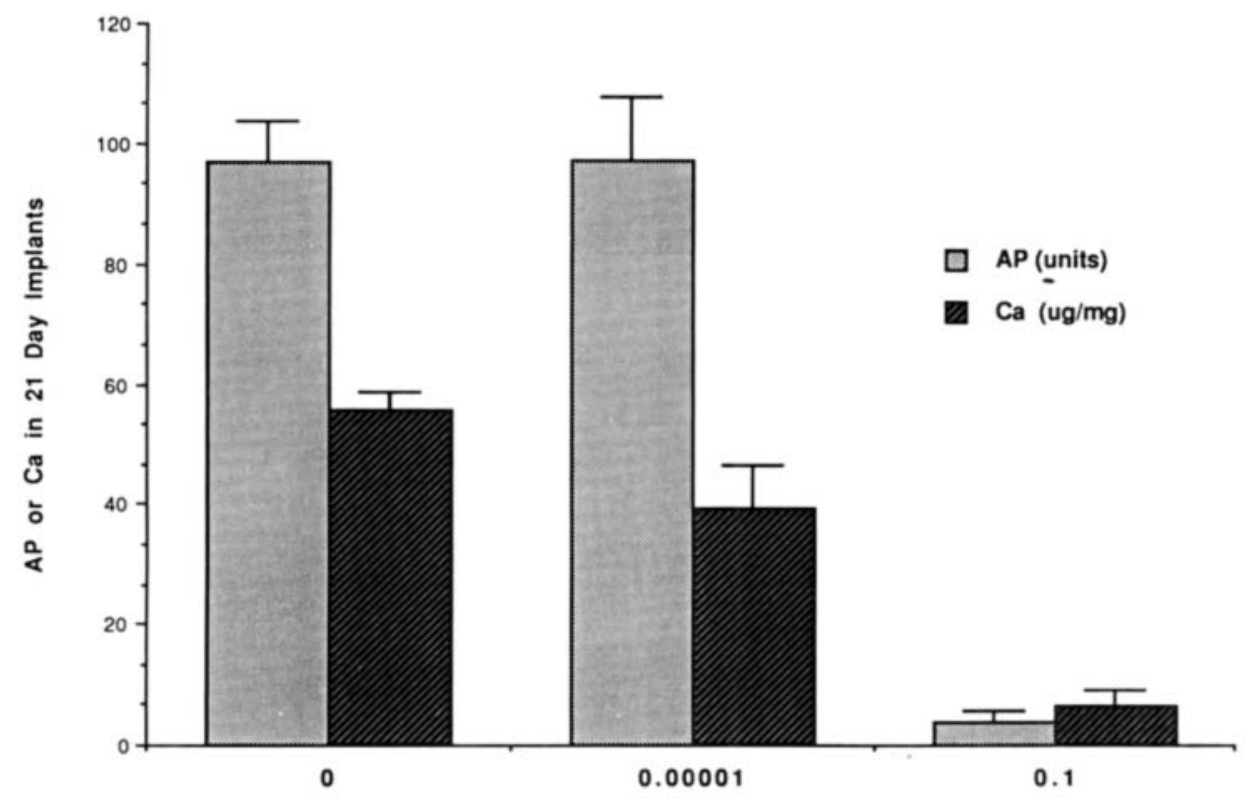

Ferric Chloride Conc. (M)

(B)

Figure 13. (continued)

formation). These enzymes include not only AP, but also ATPases, pyrophosphatase, $5^{\prime}$-nucleotidase, $p$-nppase and nucleoside triphosphate pyrophosphohydrolase ${ }^{36,72,73}$ Moreover, matrix vesicles concentrate calcium by means of high levels of Ca-binding acid phospholipids and have a membrane-invested internal microenvironment which can protect relatively soluble early mineral nuclei. Our finding of intrinsic AP activity associated with devitalized cells of GPBP imply a mechanistic role in early mineral nucleation in bioprosthetic tissues similar to that of AP in matrix vesicles of physiological calcification.

Our data suggest that the activity of intrinsic $\mathrm{AP}$ is augmented by extrinsic $\mathrm{AP}$ from the recipient, resulting in a marked increase in AP activity in the first $72 \mathrm{~h}$ of the GPBP rat subdermal implants, during which calcification is initiated. These data suggest that onset of calcification could involve both intrinsic AP activity associated with the site of the initial calcific deposits, and adsorbed extrinsic AP, which could accrue from inflammatory cells or serum, or both. Adsorbed AP could serve to provide a rapid rise in regional internal phosphate concentration sufficient to trigger calcium phosphate formation in devitalized cells. This is analogous to physiological mineralization in which matrix vesicle calcification occurs in synchrony with a peak in AP activity, but which then declines as bulk mineralization progresses. ${ }^{74}$

GPBP and porcine aortic valve tissue contain phosphorus loci within devitalized cellular structures, e.g., plasma membranes, nuclei, and mitochondria; no comparable localization of calcium is noted. ${ }^{32}$ Following implantation, calcium influx into the phosphorus-rich regions occurs between 24 and $72 \mathrm{~h}$, 


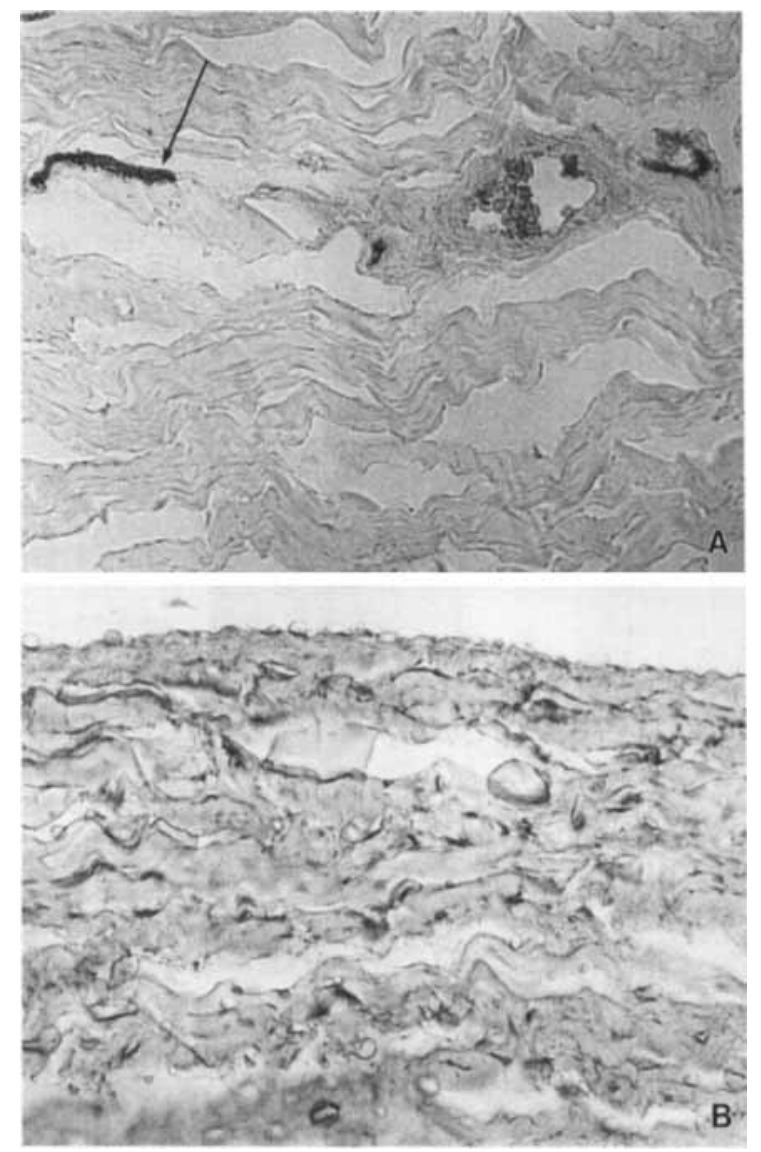

Figure 14. Histochemical demonstration of alkaline phosphatase inhibition by aluminum treatment. (A) Control glutaraldehyde-pretreated pericardial tissue. Enzyme staining of cells (dark portion product) is evident (arrow). (B) Aluminum treated tissue, similar to that in (A), demonstrating that alkaline phosphatase staining has been lost. Histochemical stain for alkaline phosphatase on cryostat sections, $375 \times$.

coincident with formation of the first mineral nuclei. ${ }^{17,20,32}$ Devitalized cells, such as those which have been exposed to glutaraldehyde fixation procedures, are not able to actively reverse the influx of ionic calcium into the phosphorus-rich cellular structures, thereby yielding crystals of calciumphosphate mineral. Furthermore, the activity of AP, both extrinsic and intrinsic, combined with this $\mathrm{Ca}^{2+}$ influx, very likely potentiates the formation of calcium phosphate salts. At these sites, AP (and likely other enzymes), both intrinsic and extrinsic, likely act by hydrolyzing phosphoesters present at the GPBP phosphorus-rich cellular loci, thus yielding free phosphate available to bind with incoming calcium, leading to calcium-phosphate crystallization. As with matrix vesicles, once the site-specific nucleation of a few seed crystals is completed, the crystal nuclei in bioprosthetic tissue serve as templates for new crystal proliferation, as a result of permissive concentrations of $\mathrm{Ca}^{2+}$ and $\mathrm{PO}_{4}{ }^{3-}$, and the local. This phase of crystal proliferation is essentially a phys- 
iochemical process, capable of regulation by promoters or inhibitors in these extracellular compartments, e.g., sufficient $\mathrm{Ca}^{2+}$ and $\mathrm{PO}_{4}{ }^{3-}$ and collagen, or low $\mathrm{Ca}^{2+} / \mathrm{PO}_{4}{ }^{3-}$, respectively and noncollagenous calcium binding proteins, such as proteoglycans, phosphoproteins and gamma carboxyglutamic acidcontaining proteins. ${ }^{36}$

\section{Alkaline phosphatase and the mechanism of $\mathrm{FeCl}_{3}$ and $\mathrm{AlCl}_{3}$ inhibition of GPBP calcification}

Preincubation of GPBP in either $\mathrm{FeCl}_{3}$ and $\mathrm{AlCl}_{3}$ inhibits GPBP calcification, ${ }^{32,54}$ and are associated with reduced AP activity. The mechanistic relationships between $\mathrm{Al}^{3+}$ and $\mathrm{Fe}^{3+}$-mediated mitigation of calcification and inhibition of AP are incompletely understood. However, both $\mathrm{Al}^{3+}$ and $\mathrm{Fe}^{3+}$ restrict the crystalline growth of hydroxyapatite in vitro. ${ }^{75,76}$ Although this mechanism could, in part, be responsible for the inhibition of calcification noted in the present study, $\mathrm{Al}^{3+}$ incubation directly quenches histochemical and chemical AP activity (recall Figs. 13 and 14). AP is a metalloenzyme which requires the cooperative binding of $\mathrm{Mg}$ and $\mathrm{Zn}$ for its activity, and $\mathrm{Fe}$ and $\mathrm{Al}$ could compete for the metal binding sites. This may reduce AP activity and contribute to delayed onset of mineralization. Furthermore, $\mathrm{Al}$ and Fe may act to interfere with AP and perhaps the AP contribution to mineralization by multiple independent mechanisms. For example, $\mathrm{Al}$ and Fe preincubations would be predicted to interfere with intrinsic AP activity (i.e., that localized to devitalized GPBP cells), perhaps by mechanisms described above, and thus inhibit AP activity at sites where calcification is typically initiated. In addition, $\mathrm{Al}$ and $\mathrm{Fe}$ may also interfere with the uptake of $\mathrm{AP}$, thereby perhaps blunting or eliminating the early rise in AP activity.

\section{Alkaline phosphatase: Implications for biomaterial implant calcification}

Is AP relevant to clinical bioprosthetic valve calcification? Clearly, further studies will be required to answer this question definitively. Nevertheless, augmentation of intrinsic AP activity by adsorbed extrinsic enzyme might explain the relative time course of calcification in rat subdermal model implants (peak in several weeks), circulatory implants in large animals (peak in several months), and human valves (several years or more). The observed level of extrinsic inflammatory cells in the vicinity of (though not necessarily requiring direct contact with) the different implant sites is consistent with this notion. Moreover, perhaps progressive loss of intrinsic enzyme activity accounts for the observation that outdated clinical valves implanted in animals calcify at a reduced rate, relative to recently prepared valves. ${ }^{77}$ Furthermore, perhaps serum alkaline phosphatase could be a marker for patients likely to have accelerated mineralization. Interestingly, children (or young rats), who calcify bioprosthetic valves at a markedly accelerated rate, have higher serum levels of alkaline phosphatase than do adults (or older rats). ${ }^{78,79}$ 
Adsorption of extrinsic AP might be important to other types of biomaterial implant calcification. AP is present in blood, extracellular fluid, and urine and, therefore, AP could be readily adsorbed on and absorbed into many implantable biomaterials. For example, calcification of polyurethane in valves, artificial hearts and ventricular assist systems usually occurs in association with the deposition of devitalized cells and cellular debris, ${ }^{80}$ and perhaps adherent blood platelets, which also contain high levels of AP activity. Thus, absorbed AP could facilitate polyurethane calcification, intrauterine contraceptive device mineralization, contact lens calcification, and urinary prosthesis encrustation.

Strategies for preventing biomaterial calcification could be based on AP inhibition. Some alkaline phosphatase inhibitors interfere with physiologic mineralization. For example, levamisole, a reversible noncompetitive inhibitor of $\mathrm{AP}$, inhibits the mineralization of cartilage in organ culture, whereas its stereoisomer, dexamisole, inhibits neither AP nor cartilage mineralization. ${ }^{81}$ Calcification inhibitors described previously for bioprosthetic valves might act in part through effects on alkaline phosphatase-dependent mechanisms. For example, sodium dodecyl sulfate (SDS), used to extract and purify $\mathrm{AP}^{82}$ may act by removing part or all of the intrinsic AP present in the bioprosthetic tissue, rendering it temporarily less calcifiable until additional absorption can take place. Variable absorption could account for the disparate results of several reported studies (reviewed in Refs. 2, 6-8). Diphosphonates inhibit alkaline phosphatase (83); diphosphonates are structurally related to pyrophosphate, a well known physiologic inhibitor of calcification and also an AP substrate, whose anticalcification potential is neutralized by AP. Preventing of AP uptake by biomaterial surface modification might lead to reduction in pathologic calcification.

The authors are appreciative of the long-term expert technical assistance of Sara Murray and Helen Shing, who have contributed greatly to the productivity of these studies. The authors also thank Claudia Davis, and Catherine Wongstrom, who assisted in the preparation of this paper.

\section{References}

1. F. J. Schoen, "Biomaterials-associated infections, neoplasia and calcification: Clinicopathologic features and pathophysiologic concepts," Trans. Am. Soc. Artif. Intern. Organs, 33, 8 (1987).

2. F. J. Schoen, H. Harasaki, K. M. Kim, et al., "Biomaterial-associated calcification: Pathology, mechanisms, and strategies for prevention," J. Biomed. Mater. Res. Appl. Biomater., 22, 11 (1988).

3. Y. Pathak, F. J. Schoen, R. J. Levy, "Pathologic calcification of biomaterials," in Biomaterials Science: An Introductory Text, B. D. Ratner and A.S. Hoffman (eds.), Academic Press, Orlando, 1990.

4. F. J. Schoen and C.E. Hobson, "Anatomic analysis of removed prosthetic heart valves: Causes of failure of 33 mechanical valves and 58 bioprostheses, 1980-1983," Hum. Pathol., 16, 549 (1985).

5. F. J. Schoen, J. Fernandez, L. Gonzalez-Lavin, et al., "Causes of failure and pathologic findings in surgically-removed Ionescu-Shiley stan- 
dard bovine pericardial heart valve prostheses: Emphasis on progressive structural deterioration," Circulation, 76, 618 (1987).

6. R. J. Levy, F. J. Schoen, and G. Golomb, "Bioprosthetic heart valve calcification: Clinical features, pathobiology, and prospects for prevention," CRC. Crit. Rev. in Biocompat., 2, 147 (1986).

7. F. J. Schoen, "Cardiac valve prostheses: Pathological and bioengineering considerations," J. Cardiac. Surg., 2, 65 (1987).

8. F. J. Schoen, J. L. Kujovich, R. J. Levy, and M. St. John Sutton, “Bioprosthetic heart valve pathology: Clinicopathologic features of valve failure and pathobiology of calcification," Cardiovasc. Clin., 18, 289 (1988).

9. F. J. Schoen, Interventional and Surgical Cardiovascular Pathology: Clinical Correlations and Basic Principles, W. B. Saunders, Philadelphia, 1989.

10. F. J. Schoen, "Pathology of bioprostheses and other tissue heart valve replacements," in Cardiovascular Pathology, 2nd Ed., M.D. Silver (ed.), Churchill Livingstone, New York, 1990.

11. S. L. Hilbert, V. J. Ferrans, Y. Tomita, et al., "Evaluation of explanted polyurethane trileaflet cardiac valve prosthesis," J. Thorac. Cardiovasc. Surg., 94, 419 (1987).

12. F. Nistal, V. Garcia-Martinez, E. Arbe, et al., "In-vivo experimental assessment of polytetrafluoroethylene trileaflet heart valve prosthesis," J. Thorac. Cardiovasc. Surg., 99, 1074 (1990).

13. W.S. Pierce, J.H. Donachy, G. Rosenberg, et al., "Calcification inside artificial hearts: Inhibition by warfarin sodium," Science, 208, 601 (1980).

14. J. B. Lian, R. J. Levy, W. Bernhard, et al., "LVAD mineralization of gamma-carboxyglutamic acid containing proteins in normal and pathologically mineralized tissue," Trans. Am. Soc. Artif. Intern. Organs, 27, 683 (1981).

15. H. Harasaki, A. Moritz, N. Uchida, et al., "Initiation and growth of calcification in polyurethane-coated blood pump," Trans. Am. Soc. Artif. Intern. Organs, 33, 643 (1987).

16. R. J. Levy, J.A. Zenker, and W.F. Bernhard, "Porcine bioprosthetic valve calcification in bovine left ventricle-aorta shunts: Studies of the deposition of vitamin K-dependent proteins," Ann. Thorac. Surg., 36, 187 (1983).

17. F. J. Schoen, R. J. Levy, A.C. Nelson, et al., "Onset and progression of experimental bioprosthetic heart valve calcification," Lab. Invest., 52, 523 (1985).

18. R. J. Shemin, F. J. Schoen, R. Hein, et al., "Hemodynamic and pathological evaluation of a unileaflet pericardial bioprosthetic valve," J. Thorac. Cardiovasc. Surg., 95, 912 (1988).

19. R. J. Levy, F. J. Schoen, J.T. Levy, et al., "Biologic determinants of dystrophic calcification and osteocalcin deposition in glutaraldehydepreserved porcine aortic valve leaflets implanted subcutaneously in rats," Am. J. Pathol., 113, 143 (1983).

20. F. J. Schoen, J.W. Tsao, and R. J. Levy, "Calcification of bovine pericardium used in cardiac valve bioprostheses. Implications for the mechanisms of bioprosthetic tissue mineralization," Am. J. Pathol., 123, 143 (1986).

21. F. J. Schoen, J. L. Kujovich, C. L. Webb, and R. J. Levy, "Chemically determined mineral content of explanted porcine aortic valve bioprostheses: Correlation with radiographic assessment of calcification and clinical data," Circulation, 76, 1061 (1987).

22. H.N. Sabbah, M.S. Hamid, and P.D. Stein, "Mechanical factors in the degeneration of porcine bioprosthetic valves: An overview," J. Cardiac. Surg., 4, 302 (1989). 
23. R. J. Levy, F. J. Schoen, and S. L. Howard, "Mechanism of calcification of porcine bioprosthetic aortic valve cusps: Role of T-lymphocytes," Am. J. Cardiol., 52, 629 (1983).

24. D. J. Magilligan, J.W. Lewis, R. H. Heinzerling, et al., "Fate of a second porcine bioprosthetic valve," J. Thorac. Cardiovasc. Surg., 85, 362 (1983).

25. P. K. Bajpai, "Immunological aspects of treated natural tissue prostheses," in Biocompatibility of Tissue Analogs, D. F. Williams (ed.), CRC Press, Boca Raton, 1985, p. 5.

26. M. Dahm, W. D. Lyman, A. B. Schwell, et al., "Immunogenicity of glutaraldehyde-tanned bovine pericardium," J. Thorac. Cardiovasc. Surg., 99, 1082 (1990).

27. P.D. Stein, J. M. Riddle, S. R. Kemp, et al., "Effect of warfarin on calcification of spontaneously degenerated porcine bioprosthetic valves," J. Thorac. Cardiovasc. Surg., 90, 119 (1985).

28. G. Golomb, F. J. Schoen, M.S. Smith, et al., "The role of glutaraldehydeinduced crosslinks in calcification of bovine pericardium used in cardiac valve bioprostheses," Am. J. Pathol, 127, 122 (1987).

29. F. J. Schoen and R. J. Levy, "Pathophysiology of bioprosthetic heart valve calcification," in Biological and Bioprosthetic Valves, E. Bodnar and M. H. Yacoub (eds.), Yorke, New York, 1986, p. 418.

30. V. J. Ferrans, S.W. Boyce, M. E. Billingham, et al., "Calcific deposits in porcine bioprostheses: Structure and pathogenesis," Am. J. Cardiol., 46, $721(1980)$.

31. M. Valente, U. Bortolotti, and G. Thiene, "Ultrastructural substrates of dystrophic calcification in porcine bioprosthetic valve failure," Am. J. Pathol., 119, 12 (1985).

32. C. L. Webb, F. J. Schoen, A.C. Alfrey, et al., "Inhibition of mineralization of glutarladehyde-pretreated bovine pericardium by $\mathrm{AlCl}_{3}$ and other metallic salts in rat subdermal model studies," Am. J. Pathol., in press.

33. R. J. Levy, F. J. Schoen, F. S. Sherman, et al., "Calcification of subcutaneously implanted Type I collagen sponges: Effects of glutaraldehyde and formaldehyde pretreatments," Am. J. Pathol., 122, 71 (1986).

34. M. J. Glimcher, "On the form and function of bone: From molecules to organs, Wolff's law revisited," in The Chemistry and Biology of Mineralized Connective Tissues, A. Veis (ed.), North Holland, Elsevier, New York, 1981, p. 617.

35. H.C. Anderson, "Calcific diseases. A concept," Arch. Pathol. Lab. Med., 107, 341 (1983).

36. H.C. Anderson, "Biology of Disease: Mechanism of mineral formation in bone," Lab. Invest., 60, 320 (1989).

37. K. M. Kim, J. M. Valigorsky, W. J. Mergner, et al., "Aging changes in the human aortic valve in relation to dystrophic calcification," Hum. Pathol, 7, 47 (1976).

38. A. Tanimura, D. H. McGregor, and H.C. Anderson, "Matrix vesicles in atherosclerotic calcification," Proc. Soc. Exp. Biol. Med., 172, 173 (1983).

39. M. J. Weiss, D. E. Cole, K. Ray, et al., "Missense mutation in the human liver-bone-kidney alkaline phosphatase gene causing a lethal form of hypophosphatasia," Proc. Nat. Acad. Sci. USA, 85, 7666 (1988).

40. A.R. Maranto and F. J. Schoen, "Alkaline phosphatase activity of glutaraldehyde-treated bovine pericardium used in bioprosthetic heart valves," Circ. Res., 63, 844 (1988).

41. R.G.G. Russell and R.Smith, "Diphosphonates. Experimental and clinical aspects," J. Bone Joint Surg., 55, 66 (1973).

42. R. J. Levy, M. A. Hawley, F. J. Schoen, et al., "Inhibition by diphosphonate compounds of calcification of porcine bioprosthetic heart valve cusps implanted subcutaneously in rats," Circulation, 71, 349 (1985). 
43. R. J. Levy, F. J. Schoen, S. A. Lund, et al., "Prevention of leaflet calcification of bioprosthetic heart valves with diphosphonate injection therapy. Experimental studies of optimal dosages and therapeutic durations," J. Thorac. Cardiovasc. Surg., 94, 551 (1987).

44. R. J. Levy, J. Wolfrum, F. J. Schoen, et al., "Inhibition of calcification of bioprosthetic heart valves by local controlled-release diphosphonate," Science, 228, 190 (1985).

45. G. Golomb, M. Dixon, M.S. Smith, et al., "Inhibition of bioprosthetic heart valve calcification by sustained local delivery of $\mathrm{Ca}$ and $\mathrm{Na}$ diphosponate via controlled release matrices," Trans. Am. Soc. Artif. Intern. Organs, 32, 587 (1986).

46. G. Golomb, R. Langer, F. J. Schoen, et al., "Controlled release of diphosphonate to inhibit bioprosthetic heart valve calcification: Doseresponse and mechanistic studies," J. Control. Rel., 4, 181 (1987).

47. G. Golomb, M. Dixon, M.S. Smith, et al., "Controlled release drug delivery of diphosphonates to inhibit bioprosthetic heart valve calcification: Release rate modulation with silicone matrices via drug solubility and membrane coating," J. Pharm. Sci., 76, 271 (1987).

48. T. J. Johnston, E. L. Bove, S. F. Bolling, et al., "Local controlled-released of 1-hydroxyethylene diphosphonate using silicone-rubber matrices: Effects of sterilization in in-vitro release and in-vitro efficacy," Trans. Am. Soc. Artif. Intern. Organs, 34, 835 (1988).

49. T. P. Johnston, E. L. Bove, S.F. Bolling, et al., "Controlled release of 1-hydroxyethylidene diphosphonate: In-vitro assesssment and effects on bioprosthetic calcification in sheep tricuspid valve replacements," Int. J. Pharm., 52, 139 (1989).

50. T. P. Johnson, J. A. Boyd, B. L. Ciesliga, et al., "Controlled release of ethanehydroxy diphosphonate from polyurethane reservoirs to inhibit calcification of bovine pericardium used in bioprosthetic heart valves. Int. J. Pharm., 59, 95 (1990).

51. Y. Pathak, J. Boyd, F. J. Schoen, et al., "Prevention of calcification of glutaraldehyde pretreated bovine pericardium through controlled release polymeric implants: Studies of $\mathrm{Fe} 3+, \mathrm{Al} 3+$, protamine sulfate and levamisole," Biomaterials, 118, 718 (1990).

52. C. L. Webb, J. J. Benedict, F. J. Schoen, et al., "Inhibition of bioprosthetic heart valve calcification with aminodiphosphonate covalently bound to residual aldehyde groups," Ann. Thorac. Surg., 46, 309 (1988).

53. C. L. Webb, F. J. Schoen, and R. J. Levy, "Covalent binding of aminopropanehydroxy-diphosphonate to glutaraldehyde residues in pericardial bioprosthetic tissue: stability and calcification inhibition studies," Exp. Mol. Pathol., 50, 291 (1989).

54. C. L. Webb, W. E. Flowers, C. Horton, et al., "Long-term efficacy of $\mathrm{Al}^{3+}$ for prevention of bioprosthetic heart valve calcification," Trans. Am. Soc. Artif. Int. Organs, 36, M408 (1990).

55. H. M. Cushner and N. D. Adams "Renal osteodystrophy: Pathogenesis and treatment," Am. J. Med. Sci., 290, 234 (1985).

56. M. O'Connor, P. Garrett, M. Dockery, et al., "Aluminum-related bone disease: Correlation between symptoms, osteoid volume, and aluminum staining," Am. J. Clin. Pathol., 86, 168 (1986).

57. P. Ackrill, J. P. Day, and R. Ahmed, "Aluminum and iron overload in chronic dialysis," Kidney Int., 33, S163 (1988).

58. K. R. Phelps, V. J. Vigorita, M. Bansal, and T. A. Minhorn, "Histochemical demonstration of iron but not aluminum in a case of dialysisassociated osteomalacia," Am. J. Med., 84, 775 (1988).

59. R. A. Clark and G. L. Krueger, "Aluminon: Its limited application as a reagent for the detection of aluminum species," J. Histochem. Cytochem., 33, 729 (1985). 
60. N. A. Maloney, S. M. Ott, A.C. Alfrey, et al., "Histological quantitation of aluminum in iliac bone from patients with renal failure," J. Lab. Clin. Med., 99, 206 (1982).

61. G.W. Cyboron, M.S. Vejins, and R.E. Wuthier, "Activity of epiphyseal cartilage membrane alkaline phosphatase and the effects of its inhibitors at physiological pH," J. Biol. Chem., 257, 4141 (1982).

62. M. Borgers, "The cytochemical application of new potent inhibitors of alkaline phosphatases," J. Histochem. Cytochem., 21, 812 (1973).

63. Division of Research Resources, NIH, DHEW and Association of American Medical Colleges: Cost Analysis and Rate Setting Manual for Animal Resource Facilities, Jan. 1975.

64. Committee on Care and Use of Laboratory Animals: Guide for the Care and Use of Laboratory Animals. DHEW Publ. No. (NIH) 78-23, Institute of Laboratory Animal Resources, NRC, 1978.

65. M. J. Karnovsky, "A formaldehyde-glutaraldehyde fixative of high osmolality for use in electron microscopy," J. Cell Biol., 27, 137A (1965).

66. O.H. Lowry, N.O. Rosebrough, and A. L. Farr, "Protein measurement with the Folin phenol reagent," J. Biol. Chem., 193, 265 (1951).

67. G.W. Wuthier and R. E. Wuthier, "Purification and initial characterization of intrinsic membrane-bound alkaline phosphatase from chicken epiphyseal cartilage," J. Biol. Chem., 256, 7262 (1981).

68. G. Gomori, "Alkaline phosphatase of cell nuclei," J. Lab. Clin. Med., 37, 526 (1951).

69. H.C. Anderson, "Electron microscopic studies of induced cartilage development and calcification," J. Cell Biol., 35, 81 (1967).

70. E. Bonucci, "Fine structure of early cartilage calcification," J. Ultrastruct. Res., 20, 33 (1967).

71. G.W. Bernard and D.C. Pease, "An electron microscopic study of initial intramembranous osteogenesis," Am. J. Anat., 125, 271 (1969).

72. S.Y. Ali, S.W. Sajdera, H.C. Anderson, "Isolation and characterization of calcifying matrix vesicles from epiphyseal cartilage," Proc. Nat. Acad. Sci. USA, 67, 1513 (1970).

73. R. J. Majeska and R. E. Wuthier, "Studies on matrix vesicles isolated from chicken epiphyseal cartilage. Association of pyrophosphatase and ATPase activities with alkaline phosphatase," Biochim. Biopphys. Acta, 391, 51 (1975).

74. B. R. Eenge, G. R. Sauer, L. N.Y. Wu, et al., "Correlation between loss of alkaline phosphatase activity and accumulation of calcium during matrix vesicle-mediated mineralization," J. Biol. Chem., 263, 18513 (1988).

75. N.C. Blumenthal, "Binding of aluminum hydroxyapatite and amorphous calcium phosphate as a model for aluminum associated osteomalacia," in The Chemistry and Biology of Mineralized Tissues. W.T. Butler, (ed.), Ebsco Press, Birmingham, 1985, p. 385.

76. J. L. Meyer and W.C. Thomas, "Trace metal-citric acid complexes as inhibitors of calcification and crystal growth," J. Urol., 128, 1372 (1982).

77. P. J. Schryer, E. R. Tomasek, J. A. Starr, et al., "Anticalcification effect of glutaraldehyde-preserved valve tissue stored for increasing in glutaraldehyde," in E. Bodnar and M. Yacoub (eds.), Biologic and Bioprosthetic Valves, Yorke Medical Books, New York, 1986, p. 471.

78. A.G. Cherian and J.G. Hill, "Age dependence of serum enzymatic activities (alkaline phosphatase, apatite aminotransferase, and creatine kinase) in healthy children and adolescents," Am. J. Clin. Pathol., 70, 783, (1978).

79. S.T. Wolferd, R. A. Schroer, P.O. Gallo, et al., "Age-related changes in serum chemistry and hematology values in normal Sprague-Dawley rats," Fund. Appl. Toxicol., 8, 80 (1987). 
80. H. Harasaki, J. McMahon, T. Richards, et al., "Calcification in cardiovascular implants: Degraded cell related phenomena," Trans. Am. Soc. Artif. Intern. Organs, 31, 489 (1985).

81. M. D. Fallon, M. P. Whyte, and S. Teitlebaum, "Stereospecific inhibition of alkaline phosphatase by L-tetramisole prevents in vitro cartilage calcification," Lab. Invest., 43, 489 (1980).

82. D. Rosenblum and S. J. Petzold, "Granuloyte alkaline phosphatase studies of purified enzymes from normal subjects and patients with polycy themia vera," J. Clin. Invest., 52, 1665 (1973).

83. H. Shinoda, G. Adomek, R. Felix, et al., "Structure-activity relationships of various bisphosphonates," Calcif. Tissue Int., 35, (1983).

Received October 10, 1990

Accepted February 6, 1991 